\begin{tabular}{|c|c|}
\hline Title & $\begin{array}{l}\text { Diurnal ozone variations in the stratosphere revealed in observations from the Superconducting Submillimeter-W ave } \\
\text { Limb-Emission Sounder (SMILES) on board the International Space Station (ISS) }\end{array}$ \\
\hline Author(s) & $\begin{array}{l}\text { Sakazaki, Takatoshi; Fujiwara, Masatomo; Mitsuda, Chihiro; Imai, Koji; Manago, Naohiro; Naito, Yoko; Nakamura, } \\
\text { Tetsu; A kiyoshi, Hideharu; Kinnison, Douglas; Sano, T akuki; Suzuki, Makoto; Shiotani, Masato }\end{array}$ \\
\hline Citation & $\begin{array}{l}\text { Journal of Geophy sical Research: A tmospheres, 118(7), 2991-3006 } \\
\text { https://doi.org/0.1002/grd.50220 }\end{array}$ \\
\hline Issue Date & $2013-0416$ \\
\hline Doc URL & http:/hdl.handle.net/2115/64748 \\
\hline Rights & Copyright 2013 A merican Geophysical Union. \\
\hline Type & article \\
\hline File Information & Sakazaki_et_al-2013_Journal_of_Geophysical_Research_A tmospheres.pdf \\
\hline
\end{tabular}

Instructions for use 


\title{
Diurnal ozone variations in the stratosphere revealed in observations from the Superconducting Submillimeter-Wave Limb-Emission Sounder (SMILES) on board the International Space Station (ISS)
}

\author{
Takatoshi Sakazaki, ${ }^{1}$ Masatomo Fujiwara, ${ }^{1}$ Chihiro Mitsuda, ${ }^{2}$ Koji Imai, ${ }^{3}$ \\ Naohiro Manago, ${ }^{4}$ Yoko Naito, ${ }^{5}$ Tetsu Nakamura, ${ }^{6}$ Hideharu Akiyoshi, ${ }^{7}$ \\ Douglas Kinnison, ${ }^{8}$ Takuki Sano, ${ }^{9}$ Makoto Suzuki, ${ }^{9}$ and Masato Shiotani ${ }^{10}$ \\ Received 2 August 2012; revised 20 January 2013; accepted 22 January 2013; published 11 April 2013.
}

[1] Considerable uncertainties remain in the global pattern of diurnal variation in stratospheric ozone, particularly lower to middle stratospheric ozone, which is the principal contributor to total column ozone. The Superconducting Submillimeter-Wave LimbEmission Sounder (SMILES) attached to the Japanese Experiment Module (JEM) on board the International Space Station (ISS) was developed to gather high-quality global measurements of stratospheric ozone at various local times, with the aid of superconducting mixers cooled to $4 \mathrm{~K}$ by a compact mechanical cooler. Using the SMILES dataset, as well as data from nudged chemistry-climate models (MIROC3.2-CTM and SD-WACCM), we show that the SMILES observational data have revealed the global pattern of diurnal ozone variations throughout the stratosphere. We also found that these variations can be explained by both photochemistry and dynamics. The peak-to-peak difference in the stratospheric ozone mixing ratio (total column ozone) reached $8 \%(1 \%)$ over the course of a day. This variation needs to be considered when merging ozone data from different satellite measurements and even from measurements made using one specific instrument at different local times.

Citation: Sakazaki, T., M. Fujiwara, C. Mitsuda, K. Imai, N. Manago, Y. Naito, T. Nakamura, H. Akiyoshi, D. Kinnison, T. Sano, M. Suzuki, and M. Shiotani (2013), Diurnal ozone variations in the stratosphere revealed in observations from the Superconducting Submillimeter-Wave Limb-Emission Sounder (SMILES) on board the International Space Station (ISS), J. Geophys. Res. Atmos., 118, 2991-3006, doi:10.1002/jgrd.50220.

\section{Introduction}

[2] Stratospheric ozone plays a crucial role in the climate system through radiative processes, and the resulting dynamical processes, such as maintenance of the stratospheric

\footnotetext{
${ }^{1}$ Graduate School of Environmental Science, Hokkaido University, Sapporo, Japan.

${ }^{2}$ Fujitsu FIP Corporation, Tokyo, Japan

${ }^{3}$ TOME R\&D Inc., Kawasaki, Japan.

${ }^{4}$ Center for Environmental Remote Sensing, Chiba University, Chiba, Japan.

${ }^{5}$ Graduate School of Science, Kyoto University, Kyoto, Japan.

${ }^{6}$ National Institute of Polar Research, Tachikawa, Japan.

${ }^{7}$ Center for Global Environmental Research, National Institute for Environmental Studies, Tsukuba, Japan.

${ }^{8}$ National Center for Atmospheric Research, Boulder, USA.

${ }^{9}$ Institute of Space and Astronautical Science, Japan Aerospace Exploration Agency, Sagamihara, Japan.

${ }^{10}$ Research Institute for Sustainable Humanosphere, Kyoto University, Uji, Japan.
}

Corresponding author: T. Sakazaki, Graduate School of Environmental Science, Hokkaido University, Sapporo, Japan. (zaki@ees.hokudai.ac.jp)

C2013. American Geophysical Union. All Rights Reserved. 2169-897X/13/10.1002/jgrd.50220 thermal/wind structure and the excitation of solar thermal tides [Chapman and Lindzen, 1970]. Study of diurnal variations in ozone concentration is important not only to improve our understanding of the processes involved but also to improve estimation of inter-annual variations and long-term trends based on measurements from different locations and different local times or measurement with a local time that changes during the monitoring period.

[3] Diurnal variations in the upper stratosphere and mesosphere have been extensively studied because of their large amplitude ( $>10 \%$ to the daily mean) [Vaughan, 1982; Zommerfelds et al., 1989; Ricaud et al., 1996; Marsh et al., 2002; Schneider et al., 2005; Huang et al., 2008; Dikty et al., 2010]. At these altitudes, ozone levels show a strong depletion during the daytime but then recover at night. This day-night contrast is explained by diurnal variations in the photochemically driven partitioning of $\mathrm{O}$ and $\mathrm{O}_{3}$ [e.g., Vaughan, 1982; Zommerfelds et al., 1989].

[4] In contrast, few studies have considered diurnal variations in the lower to middle stratosphere that contribute mainly to variations in total column ozone (see below). In the stratosphere, diurnal ozone variations are almost the same as those seen in odd oxygen $\left(\mathrm{O}_{x}=\mathrm{O}+\mathrm{O}_{3}\right)$, because 
$\left[\mathrm{O}_{x}\right]$ is approximately equal to $\left[\mathrm{O}_{3}\right]$ at this altitude. The photochemical lifetime of ozone (odd oxygen) is a few weeks at $30 \mathrm{~km}$, and decreases exponentially to around 1 day at $40 \mathrm{~km}$, and a few hours at 50-60 km [Brasseur and Solomon, 2005]; consequently, both photochemistry and dynamics are expected to contribute to diurnal ozone variations in the stratosphere.

[5] In terms of photochemistry, Pallister and Tuck [1983] used a 1-D photochemical model to investigate diurnal ozone variations at the spring equinox in the middle to upper stratosphere at latitude $34.3^{\circ} \mathrm{N}$. They found that below $42 \mathrm{~km}$, ozone reaches a minimum (approximately $-1 \%$ ) after sunset due to $\mathrm{NO}_{x}$ chemistry and is at its maximum concentration (approximately $+4 \%$ ) in the afternoon due to photolysis of molecular oxygen, while above $42 \mathrm{~km}$, ozone levels are lowest (approximately $-5 \%$ ) around noon due to $\mathrm{HO}_{x}$ chemistry.

[6] In terms of dynamics, vertical transport due to atmospheric tides is expected to contribute to diurnal ozone variations at altitudes where background ozone levels have a sharp vertical gradient. This contribution can be roughly estimated from diurnal temperature variations using the following linearized equation [cf. Huang et al., 1997] in $\log$-pressure coordinates $\left(z^{*}\right)$ :

$$
\frac{\partial\left[O_{3}\right]{ }^{\prime}{ }_{D} V T}{\partial t}=-w^{*} \frac{\partial\left[\overline{O_{3}}\right]}{\partial z^{*}}=-\frac{R}{H N^{2}} \frac{\partial\left[\overline{O_{3}}\right]}{\partial z^{*}}\left(\frac{\partial T}{\partial t}-J\right)
$$

[7] where $\left[\overline{\mathrm{O}}_{3}\right]$ is the daily-mean ozone mixing ratio, $\left[\mathrm{O}_{3}\right]_{\text {'D VT }}$ is the daily-anomaly ozone mixing ratio caused by vertical transport, $t$ is time, $w^{*}$ is vertical velocity, $R\left(=287 \mathrm{~J} \mathrm{~kg}^{-1} \mathrm{~K}\right)$ is the gas constant for dry air, $H$ is the scale height (approximately $7 \mathrm{~km}$ ), $N^{2}$ is the static stability (approximately $4.0 \times 10^{-4} \mathrm{~s}^{-2}$ in the stratosphere), $T$ is the daily temperature-anomaly temperature (temperature tides), and $J$ is the diabatic heating rate $\left(\mathrm{K} \mathrm{s}^{-1}\right)$. Sun-synchronous diurnal temperature variations (i.e., the diurnal variations that propagate westward with the apparent motion of the Sun) in the lower stratosphere were investigated by Zeng et al. [2008] and Sakazaki et al. [2012], who showed that the amplitude of temperature variations $\left(T^{3}\right)$ in the lower stratosphere is around $0.5 \mathrm{~K}$ at $25 \mathrm{~km}$ in the tropics. Sakazaki et al. (Interpretation of the vertical structure and seasonal variation of the diurnal migrating tide from the troposphere to the lower mesosphere, manuscript in preparation, 2013) showed that $J$ is negligible $(<20 \%)$ compared with $\partial T / \partial t$ for this altitude region. Thus, assuming that $\partial\left[\overline{\mathrm{O}}_{3}\right] / \partial \mathrm{z}$ is $1 \mathrm{ppmv} \mathrm{km}^{-1}$ in the lower stratosphere (Figure $4 \mathrm{f}$ ), the diurnal ozone variation caused by vertical transport $\left(\left[\mathrm{O}_{3}\right]^{\prime}{ }_{\text {D VT }}\right)$ can be estimated, using equation (1), to be around $0.05 \mathrm{ppmv}$ in amplitude (the value relative to the daily mean is approximately $1 \%$ for the typical daily-mean ozone mixing ratio of approximately 4 ppmv at $25 \mathrm{~km}$ ). Vertical transport may also contribute in the upper stratosphere where the negative gradient of background ozone is large; however, quantitative estimation is difficult because $J$ is non-negligible in this region.

[8] While previous studies have used models or a theoretical approach to consider diurnal ozone variations in the lower to middle stratospheres, few direct observational data have been obtained, and this is partly because these variations have such a small amplitude and therefore are difficult to detect. Haefele et al. [2008] examined diurnal ozone variations in the stratosphere using data from both ground radiometer measurements at Payerne $\left(47^{\circ} \mathrm{N}, 7^{\circ} \mathrm{E}\right)$ and two chemical climate models (CCMs). They found that in the middle stratosphere, ozone levels peak during the afternoon (approximately 3\%) possibly due to photochemical factor and that this variation agrees well with the results from the CCMs. They attributed the afternoon maxima to the photolysis of molecular oxygen. In contrast, variation in the lower stratosphere did not agree with the results from the CCMs. Two non-Sun-synchronous satellites, i.e., the Upper Atmosphere Research Satellite (UARS)/Microwave Limb Sounder (MLS) [Huang et al., 1997; Huang et al., 2010] and the Thermosphere Ionosphere Mesosphere Energetics and Dynamics (TIMED)/Sounding of the Atmosphere using Broadband Emission Radiometry (SABER) [Huang et al., 2010], were also used to analyze diurnal variations in stratospheric ozone in particular latitude bands $\left(28^{\circ} \mathrm{N}\right.$ in Huang et al. [1997]; $40^{\circ} \mathrm{S}, 0^{\circ} \mathrm{N}$, and $40^{\circ} \mathrm{N}$ in Huang et al. [2010]). The variations in the middle and upper atmospheres were essentially similar to those reported by Haefele et al. [2008]. Huang et al. [2010] showed that the maximum appears in the afternoon between $\sim 30 \mathrm{~km}(10 \mathrm{hPa})$ and $\sim 45 \mathrm{~km} \mathrm{(1} \mathrm{hPa)} \mathrm{while} \mathrm{above} \sim 45 \mathrm{~km}$, the afternoon values become smaller than the nighttime values. They also showed that these features are seen both in the tropics $\left(0^{\circ} \mathrm{N}\right)$ and in mid-latitudes $\left(40^{\circ} \mathrm{S}, 40^{\circ} \mathrm{N}\right)$. These variations were mostly attributed to photochemistry, while Huang et al. [1997] also inferred that dynamics might be a contributory factor in the upper stratosphere. However, it should be noted that in the lower stratosphere, these satellite observations (both MLS and SABER) indicated considerably large amplitudes (approximately $10 \%$ to the nighttime value) [Huang et al., 2008], which is too large when compared with our estimation above.

[9] Consequently, the global pattern of diurnal variations in stratospheric ozone is yet to be established, including the detailed latitude and altitude dependency, particularly in the lower stratosphere. In addition, the underlying mechanism, including the relative contributions from photochemistry and dynamics, remains uncertain throughout the stratosphere.

[10] The Superconducting Submillimeter-Wave LimbEmission Sounder (SMILES) attached to the Japanese Experiment Module (JEM) on board the International Space Station (ISS) made global observations of the minor constituents in the middle atmosphere (e.g., $\mathrm{O}_{3}, \mathrm{HCl}$, and $\mathrm{ClO}$ ), in the $600 \mathrm{GHz}$ region between October 2009 and April 2010. One of the important aspects of these measurements was their high sensitivity, which was facilitated by the superconducting mixers cooled to $4 \mathrm{~K}$ by a three-stage mechanical cooler [Kikuchi et al., 2010]. In addition, SMILES measured the atmosphere at different local times because of the nonSun-synchronous nature of the orbit of the ISS. This dataset provides unprecedented opportunities to study diurnal ozone variations throughout the stratosphere.

[11] In this study, SMILES data were analyzed to quantify diurnal variations in stratospheric ozone, while two CCMs (MIROC3.2-CTM and SD-WACCM) whose dynamical variables were nudged toward global (re)analysis data were used to supplement our results. Hereafter, these nudged CCMs are simply referred to as chemistry-transport models (CTMs) to emphasize the point that unlike CCM data, CTM data can be compared with observational data on a 
specific date and time. We demonstrate that the SMILES observations have revealed the global pattern of diurnal variations in stratospheric ozone and also the resulting stratospheric column ozone, without, at least in low-latitude regions, being affected by sampling issues related to inhomogeneous measurements. The contributions from photochemistry and dynamics are examined by analyzing CTM results. The remainder of the manuscript is organized as follows. Sections 2 and 3 describe the datasets and analysis methods, respectively. Section 4 describes the diurnal variations in stratospheric ozone levels and total column ozone and considers the controlling processes, while section 5 summarizes our main findings.

\section{Data Description}

[12] We analyzed the ozone mixing ratio between 20 and $60 \mathrm{~km}$ during the SMILES observation period from October 2009 to April 2010 using three observational/model datasets

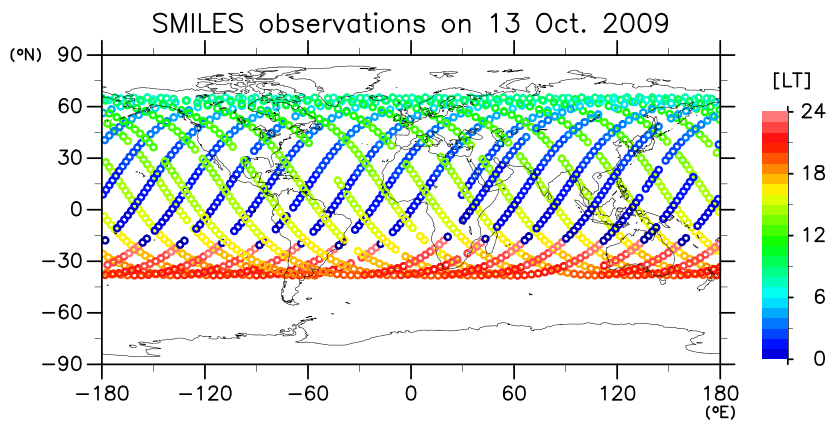

Figure 1. SMILES measurement tracks on 13 October 2009. Color indicates the measurement local time (see the color bar on the right-hand side). as follows: (1) SMILES Version 2.0 Level 2 products, (2) MIROC3.2-CTM, and (3) SD-WACCM data. These datasets are described below.

\subsection{SMILES}

[13] SMILES observed the Earth's limb from the ISS at a typical altitude of between 350 and $400 \mathrm{~km}$. The ISS orbit is circular, with an inclination of $51.6^{\circ}$ to the equator, so that the highest latitude reached by the ISS is at $52^{\circ}$ north and south. At the same time, since the antenna beam is deflected $45^{\circ}$ to the left from the direction of orbital motion, SMILES nominally covered latitudes from $38^{\circ} \mathrm{S}$ to $65^{\circ} \mathrm{N}$ on each orbit within a period of $93 \mathrm{~min}$, while the latitudinal coverage was temporarily changed to the region from $65^{\circ} \mathrm{S}$ to $38^{\circ} \mathrm{N}$ during the following three periods: 19-24 November in 2009, 10-19 February in 2010, and 7-17 April in 2010. Figure 1 shows the SMILES measurement tracks with the color indicating the measurement local time on 13 October 2009. The ISS is not in a Sun-synchronous orbit, and its orbital plane rotates every 60 days (i.e., the local time of measurement changes by $24 / 60=0.4 \mathrm{~h}$ per day); thus, the observations cover a full diurnal cycle over 30 days from the ascending/descending nodes. Figure 2 shows the time series of measurement local time at the equator for the ascending and descending nodes, as averaged over longitude at the equator for each day. The period when SMILES viewed the Southern Hemisphere is shown by horizontal arrows.

[14] The SMILES has three specified detection bands within the submillimeter-wave region: 624.32-625.52 GHz (Band A), 625.12-626.32 GHz (Band B), and 649.12-650.32 GHz (Band C). The brightest ozone emission is the line at 625.37 $\mathrm{GHz}$, which is located in Bands A and B [Kikuchi et al., 2010]. The SMILES Version 2.0 Level 2 products [Takahashi et al., 2010, 2011; Mistuda et al., 2011] include the retrieved ozone profiles for the altitude region of $8-85 \mathrm{~km}$, but we used data from above $20 \mathrm{~km}$ because the accuracy of SMILES data

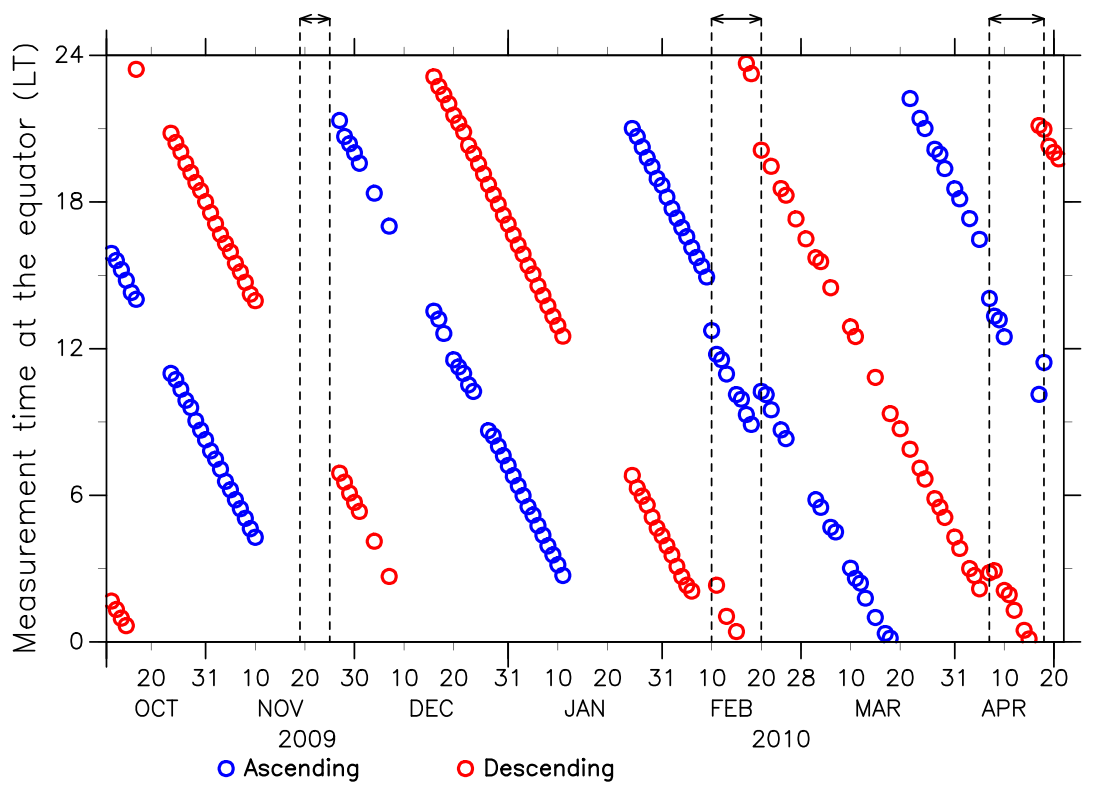

Figure 2. Measurement local time at the equator for ascending node (open blue circles) and descending node (open red circles). The region between the two dashed lines denotes the periods when the SMILES observed the Southern Hemisphere. 
in the troposphere is low due to the uncertainty associated with the continuum emission by water vapor and scattering by clouds [Takahashi et al., 2010]. The vertical resolution of the Level 2 data is $2 \mathrm{~km}$ for altitudes between 20 and $58 \mathrm{~km}$, and $3 \mathrm{~km}$ above $58 \mathrm{~km}$. Band A data were used in the present study, but we also found that that Band B data generated similar results.

[15] Imai et al. [2012a] compared ozone profiles measured by the SMILES with those obtained from worldwide ozonesonde stations and found good agreement at middle to high latitudes of within $6 \%$ to $8 \%$ between 20 and $30 \mathrm{~km}$, but at low latitudes, the difference increased to around $7 \%$ to $20 \%$; however, part of this increase ( up to $7 \%$ ) may result from bias in the ozonesonde measurements due to the response time issue. Imai et al. [2012b] compared the ozone distributions obtained from the SMILES with those obtained from the following five satellite measurements: the Microwave Limb Sounder (MLS) on the Earth Observing System (EOS) Aura satellite, the Michelson Interferometer for Passive Atmospheric Sounding (MIPAS) on the Envisat satellite, the Submillimeter Radiometer (SMR) on the Odin satellite, the SABER on the TIMED satellite, and the Atmospheric Chemistry Experiment-Fourier Transform Spectrometer (ACE-FTS) on the SCISAT-1 satellite. They revealed that the agreement with these satellite measurements was generally within $10 \%$ in the stratosphere.

\subsection{MIROC3.2-CTM and SD-WACCM}

[16] The MIROC3.2-CTM was developed at the National Institute for Environmental Studies (NIES), Japan, and incorporates the chemical module of CCSR/NIES CCM [Akiyoshi et al., 2009] into the MIROC3.2-GCM. The calculation was performed with horizontal winds nudged toward ERA-Interim reanalysis data [Dee et al., 2011]. The SDWACCM [Kunz et al., 2011] is another CTM simulation that uses the Whole Atmosphere Community Climate Model Version 4 (WACCM4) with temperature, horizontal winds, and surface pressure nudged toward the Goddard Earth Observing System-5 (GEOS-5) analysis data [Rienecker et al., 2007]. These CTMs were constrained by meteorological conditions with an hourly time scale so that they could be directly compared with the observation data, even at specific times. For the MIROC3.2-CTM (SD-WACCM), the horizontal resolution was $2.8^{\circ}\left(2.5^{\circ}\right)$ in longitude and $2.8^{\circ}$ $\left(1.9^{\circ}\right)$ in latitude; the vertical resolution was approximately $1 \mathrm{~km}$ (approximately $1 \mathrm{~km}$ ) in the upper troposphere and lower stratosphere, and 1-3 km (1-2 km) in the stratosphere; the temporal resolution of output data was $0.5 \mathrm{~h}(0.5 \mathrm{~h})$.

[17] For these CTMs, we prepared and analyzed a subset of the data that was sampled at the nearest time and grid point to the SMILES measurements; these data are referred to as CTM-SMILES. SMILES data were provided at geometric altitudes with a vertical resolution of 2-3 km, while the CTM datasets were provided primarily in pressure coordinates, which were used after being interpolated onto the SMILES altitude levels using the cubic spline method. To convert pressure levels into altitude $(z)$ levels, we used the relationship between geopotential height $(H)$ and altitude derived by Mahoney [2008, available from the web site http://mtp.mjmahoney.net/www/notes/pt_accuracy/ ptaccuracy.html] is used:

$$
\begin{aligned}
z(H, \phi)= & \left(1+2.373 \cdot 10^{-3} \cdot \cos (2 \phi) \cdot H\right. \\
& +\left(1+8.6476 \cdot 10^{-3} \cdot \cos (2 \phi)\right) \cdot \frac{H^{2}}{6.356 .6818}
\end{aligned}
$$

where $H$ is in kilometer and $\varphi$ is the latitude.

\section{Data Analysis Methods}

\subsection{Extraction of Diurnal Variations}

[18] We examine the Sun-synchronous diurnal variations (i.e., the diurnal variations that propagate westward with the apparent motion of the Sun, that is, the diurnal variations as a function of local time) for each latitude grid $\left(5^{\circ}\right)$ and every altitude level (every 2 or $3 \mathrm{~km}$ ). For temporally continuous data such as the full-grid CTM dataset (see the next paragraph), a simple local time composite during the analysis period can be used to extract the diurnal variations. However, for the satellite data such as the SMILES data, only two data at corresponding two local times are obtained for each day at each grid point (one is from ascending node and the other is from descending node). This means that background ozone changes (i.e., seasonal changes) could contaminate the diurnal variations if obtained from the simple composite analysis. To avoid these sampling issues, we extracted the diurnal variations from SMILES and CTM-SMILES following the method proposed by Forbes et al. [2008].

[19] First, as described in section 2.1 and shown in Figure 1, the difference in measurement local time over the longitude (within a day) is less than $0.4 \mathrm{~h}$. Thus, we extracted the data at the two local times (one is for ascending node and the other is for descending node) for each day, by averaging the original data for ozone over the longitude for each node independently. Figure 3 a shows the time series of the daily ozone mixing ratio at $44 \mathrm{~km}$ above the equator, with the color indicating the measurement local time. On the other hand, the measurement local time changes day by day as shown in Figure 2. Thus, daily anomalies (anomalies from the daily mean) were obtained by subtracting the 30 day running mean as calculated with both ascending and descending nodes (solid curve in Figure 3a) from the original time series (circles and crosses in Figure $3 \mathrm{a}$ ). We selected 30 days here because the diurnal cycle ( 24 local times) is covered by ascending and descending nodes over 30 days (Figure 2), so that the 30 day mean can be regarded as the daily mean. Finally, the daily anomalies were binned and averaged in $1 \mathrm{~h}$ local-time bins over the SMILES observation period, which were taken to represent the Sun-synchronous diurnal variations in this study. Figure $3 \mathrm{~b}$ shows the residuals sorted by local times (colored closed circles and crosses) and the obtained hourly diurnal variations (black open circles) at the equator at an altitude of $44 \mathrm{~km}$ as in Figure $3 \mathrm{a}$. It should be noted that in this study, we show the 6 month mean diurnal variations and that we were unable to determine the seasonal dependence within this 6 month period using SMILES data due to the small amount of data available and the occurrence of periods when no data were collected (Figure 2). However, the seasonal dependence is briefly discussed, using the CTM data (see section A for details).

[20] For the CTMs, we also extracted the Sun-synchronous diurnal variations using the full-grid datasets (referred to as CTM-ALL data) using a simple composite analysis as mentioned above. First, for the MIROC3.2-CTM (SD-WACCM), 
(a) 03 mixing ratio

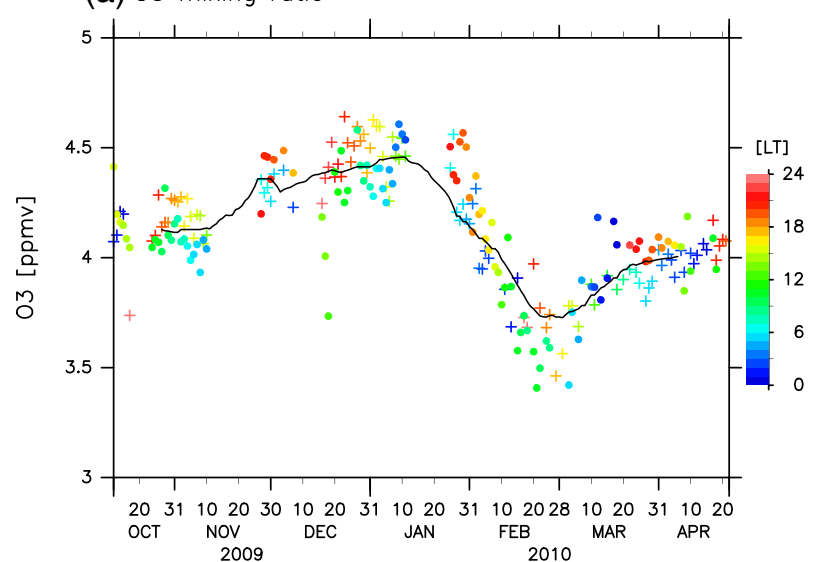

(b) Daily anomaly sorted in local time

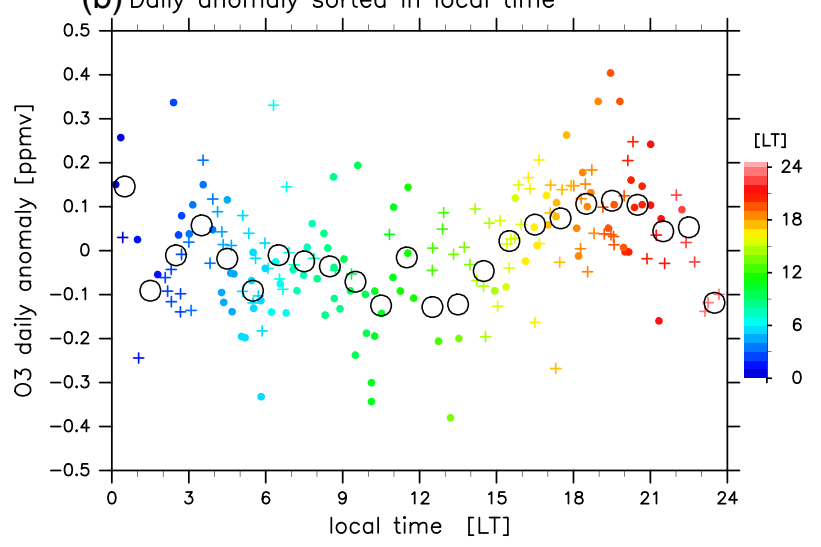

Figure 3. (a) Daily time series of ozone mixing ratio at the equator averaged over the longitude at an altitude of $44 \mathrm{~km}$, as observed by the SMILES. Closed circles and crosses denote ascending and descending nodes, respectively, with the color indicating the measurement local time (see the color bar on the right-hand side). Black solid curve shows the 30 day running mean. (b) The residual from the 30 day running mean sorted by local times. Open circles denote the hourly dailyanomaly component averaged over the analysis period.

by averaging the data for the SMILES observation period, mean 0.5 hourly ( 3 hourly) (in universal time (UT)) data were calculated at each longitude-latitude-altitude grid point. Using this data set, the daily anomalies from the daily mean were extracted. In contrast to the SMILES and CTM-SMILES, here we calculated the daily mean and the daily anomalies averaged over the analysis period. Then we binned and averaged the 0.5 hourly ( 3 hourly) anomaly data in hourly "local time" bins for MIROC3.2-CTM (SD-WACCM) to extract diurnal variations as a function of local time for each latitude-altitude grid point (i.e., Sun-synchronous diurnal variations). That is, the calculation was made using the daily-anomaly data over $24 \mathrm{~h}$ in UT, and over $360^{\circ}$ in longitude, on the latitude circle; for example, the data at 06:00 UT at $50^{\circ} \mathrm{E}$ (i.e., 09:33 LT) were binned into the hourly bin of 09:00-10:00 LT. The diurnal variation from the CTM-ALL data will be compared with that from CTM-SMILES data to evaluate the sampling issues in CTM-SMILES data (and thus SMILES data itself) that may remain even after removing the 30 day running mean (e.g., a contamination of day-to-day scale changes).
[21] Diurnal variations in the stratospheric column ozone were also calculated. For SMILES and CTM-SMILES data, the variations in diurnal ozone number density were obtained at each latitude grid point, and at each altitude level, using the same method as for the mixing ratio, and those variations were vertically integrated from $20 \mathrm{~km}$ to $64 \mathrm{~km}$. For the CTM-ALL data, we calculated the total column ozone from the surface to the top level.

\subsection{Photochemical and Dynamical Diurnal Variations of $\mathrm{O}_{x}$ in MIROC3.2-CTM}

[22] In section 4.2, we will discuss diurnal variations in ozone in terms of those in odd oxygen $\left(\mathrm{O}_{x}=\mathrm{O}+\mathrm{O}_{3}\right)$. The mixing ratio of odd oxygen $\left(\left[\mathrm{O}_{x}\right]\right)$ changes due to dynamical transport and its chemical production or loss $(S)$ and can be expressed as follows:

$$
\frac{\partial\left[O_{x}\right]}{\partial t}=-\mathbf{u} \cdot \nabla\left[O_{x}\right]+S
$$

where $t$ is time and $\boldsymbol{u}$ is the 3-D wind. MIROC3.2-CTM provides $\left[\mathrm{O}_{x}\right]$, as well as $\boldsymbol{u}$ and $S$. Diurnal variations in $\left[\mathrm{O}_{x}\right]$ were first obtained $\left(\left[\mathrm{O}_{x}\right]^{\prime}\right)$ using the $\left[\mathrm{O}_{x}\right]$ data. At the same time, we extracted the diurnal variations of $S\left(S^{\prime}\right)$, and then $S$ ' was integrated over the course of a day to obtain diurnal $\left[\mathrm{O}_{x}\right]$ variations caused by photochemistry only $\left(\left[\mathrm{O}_{x}\right]_{C}{ }_{C}\right)$. The dynamical $\left[\mathrm{O}_{x}\right]$ variations $\left(\left[\mathrm{O}_{x}\right]^{\prime}{ }_{\mathrm{D}}\right)$ were estimated as the difference between the total variations $\left(\left[\mathrm{O}_{x}\right]^{\prime}\right)$ and the photochemical variations $\left(\left[\mathrm{O}_{x}\right]^{\prime}{ }_{\mathrm{C}}\right)$ (i.e., $\left.\left[\mathrm{O}_{x}\right]^{\prime}{ }_{\mathrm{D}}=\left[\mathrm{O}_{x}\right]{ }^{\prime}-\left[\mathrm{O}_{x}\right]^{\prime}{ }_{\mathrm{C}}\right)$. Finally, we also estimated vertical transport due to the Sun-synchronous diurnal variations of vertical winds $\left(w^{\prime}\right)$ $\left(\left[\mathrm{O}_{x}\right]^{\prime}{ }_{D_{-} V T}\right)$ by integrating the following equation:

$$
\frac{\partial\left[O_{x}\right]^{\prime}{ }_{D \_} V T}{\partial t}=-w, \frac{\partial\left[\overline{O_{x}}\right]}{\partial z}
$$

where $z$ is altitude and $\left[\overline{\mathrm{O}}_{x}\right]$ is the daily and zonal mean over the analysis period. The contribution from diurnal and semidiurnal components to $w^{\prime}$ was examined using harmonic analysis. When we consider the $n$th harmonic component of $\left[\mathrm{O}_{x}\right]^{\prime}{ }_{D_{-} V \mathrm{~T}}\left(x_{n}=\operatorname{Re}\left[X_{n} \exp \left(i \omega_{n} t\right)\right]\right)$ and $w^{\prime}\left(w_{n}=\operatorname{Re}\left[W_{n}\right.\right.$ $\left.\left.\exp \left(i \omega_{n} t\right)\right]\right)$ for equation (4) $\left(\operatorname{Re}\left[{ }^{*}\right]\right.$ indicates that we take the real part of $*)$, the following relationship is obtained:

$$
X_{n}=i\left(\omega_{n}\right)^{-1} W_{n} \frac{\partial\left[\overline{O_{x}}\right]}{\partial z}
$$

where $X_{n}$ and $W_{n}$ are the complex amplitudes, $i=\sqrt{ }_{-} 1$, and $\omega_{n}=2 \pi n / 24\left(\mathrm{~h}^{-1}\right)$ is the frequency. Here $n=1$ and 2 correspond to the diurnal and semidiurnal harmonic components, respectively.

\section{Results}

[23] As described in section 3.1, we derive and discuss diurnal ozone variations averaged over the SMILES observation period, i.e., approximately a half year in the Northern Hemisphere winter. The seasonal dependence of diurnal variations within this 6 month period is estimated using the CTMs, which will be validated by SMILES throughout this study (see section A for details). We found that the timing of maxima/minima associated with diurnal variations do not change over the 6 month period in the latitude region of $40^{\circ} \mathrm{S}-40^{\circ} \mathrm{N}$, although the amplitude could change by up to 
$\sim 50 \%$ over the period. Therefore, the 6 month mean is quite a good representative of the qualitative features during the analysis period for the region of $40^{\circ} \mathrm{S}-40^{\circ} \mathrm{N}$. The following discussion is restricted to this latitude region.

\subsection{Diurnal Variations in Stratospheric Ozone}

[24] Figure 4 shows diurnal ozone variations at $24 \mathrm{~km}$, $34 \mathrm{~km}, 44 \mathrm{~km}$, and $54 \mathrm{~km}$ based on data from SMILES and the CTMs averaged over $10^{\circ} \mathrm{S}-10^{\circ} \mathrm{N}$. For the CTMs, we present two sets of results, i.e., CTM-SMILES and CTM-ALL. Results from SMILES show distinct diurnal variations that are dependent on altitude. These features are reproduced reasonably well by CTM-SMILES at all levels, although the amplitudes in the CTMs at $54 \mathrm{~km}$ are 2 or 3 times larger than those in SMILES. Furthermore, the results from CTMSMILES and CTM-ALL are in good agreement, indicating that the sampling issues caused by inhomogeneous SMILES measurements have been almost completely removed with our analysis method and are negligible (Figure 5).
[25] To demonstrate the altitude dependency more clearly, Figure 5 shows vertical distributions of diurnal ozone variations averaged over $10^{\circ} \mathrm{S}-10^{\circ} \mathrm{N}$. The SMILES results (Figure 5a) show clear diurnal variations, which are reproduced quite well in the CTM-SMILES data (Figures $5 \mathrm{~b}$ and $5 \mathrm{c}$ ). Also, the small difference between the CTM-SMILES (Figures 5b and 5c) and CTM-ALL data (Figures 5d and 5e) indicates negligible sampling issues. At 20-30 km, the ozone levels show a maximum in the morning and a minimum in the late afternoon, with an amplitude of $0.05 \mathrm{ppmv}(1 \%)$. At $30-40 \mathrm{~km}$, this situation is reversed: ozone levels are at their lowest just after dawn and increase toward a maximum in the afternoon, while they change little during the night. The amplitude reaches 0.15 ppmv ( $2 \%$ to $3 \%)$. At $40-50 \mathrm{~km}$, we observed negative values in the period 00:00-06:00 LT, slightly positive values between 06:00 and 09:00 LT, a minimum of $0.1 \mathrm{ppmv}(3 \%$ to $4 \%)$ at about noon, and an enhanced maximum of $0.1 \mathrm{ppmv}(3 \%$ to $4 \%$ ) in the late afternoon (around 18:00 LT). These regime shifts with altitude produce an apparent upward (downward) phase progression of the positive (negative) anomaly at around

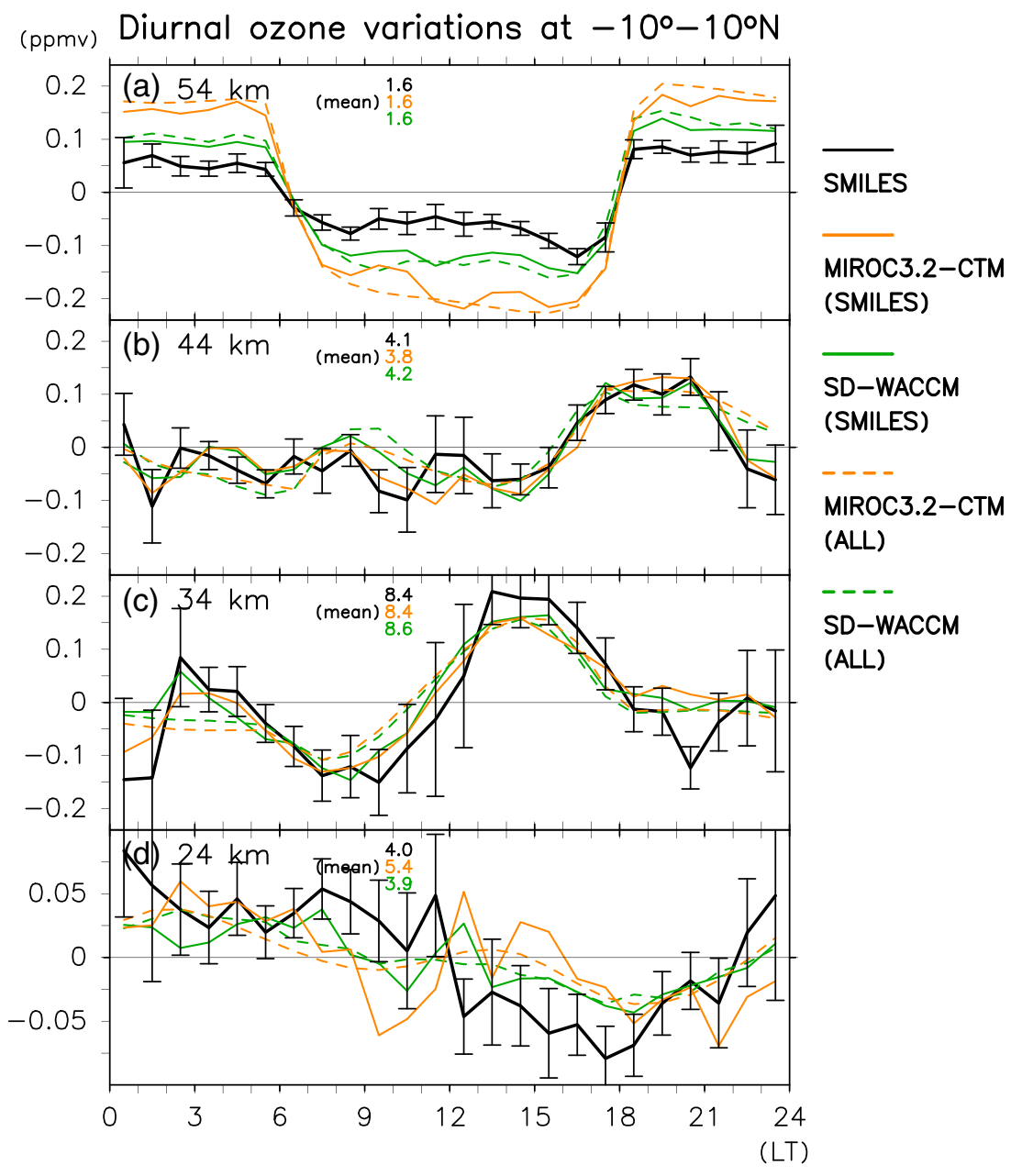

Figure 4. Diurnal ozone variations averaged over $10^{\circ} \mathrm{S}-10^{\circ} \mathrm{N}$ at altitudes of (a) $54 \mathrm{~km}$, (b) $44 \mathrm{~km}$, (c) $36 \mathrm{~km}$, and (d) $24 \mathrm{~km}$. Black solid curves are SMILES data, while vertical bars show the 95\% confidential level for the hourly composite value ( $t$-test). Orange (green) solid curves show the results from MIROC3.2-CTM (SD-WACCM) at SMILES observation locations and times. Orange (green) dashed curves show the results from the full-grid MIROC3.2-CTM (SD-WACCM) dataset. The daily-mean values (the average for the analysis period) for SMILES, MIROC3.2-CTM, and SD-WACCM (full-grid datasets) are shown with the same color allocation as the line plots. 


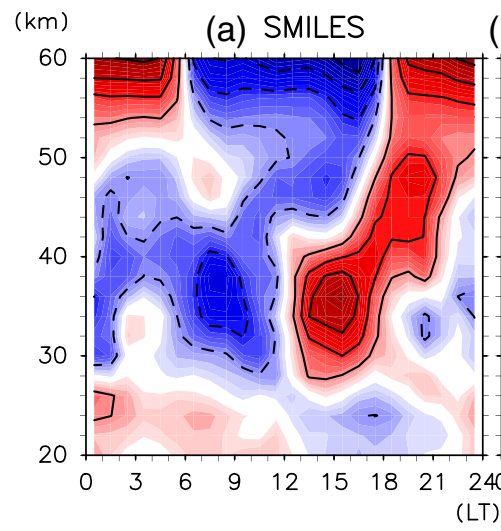

(b) MIROC3.2-CTM (SMILES)

(c) SD-WACCM (SMILES)

(f) Daily-mean
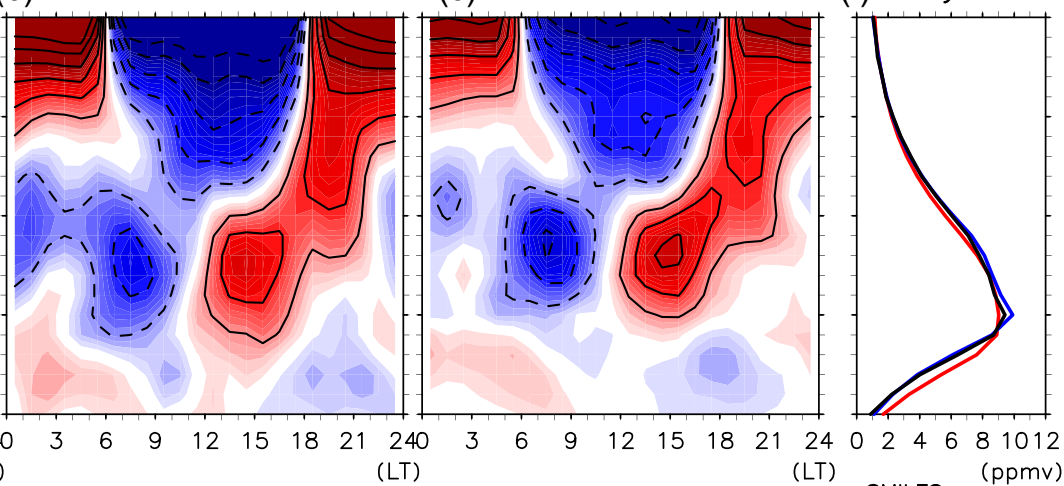

Contour_Interval $=0.05$

(d) MIROC3.2-CTM (ALL)

(e) SD-WACCM (ALL)

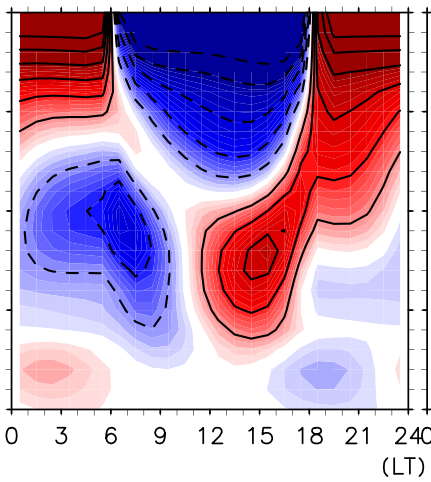

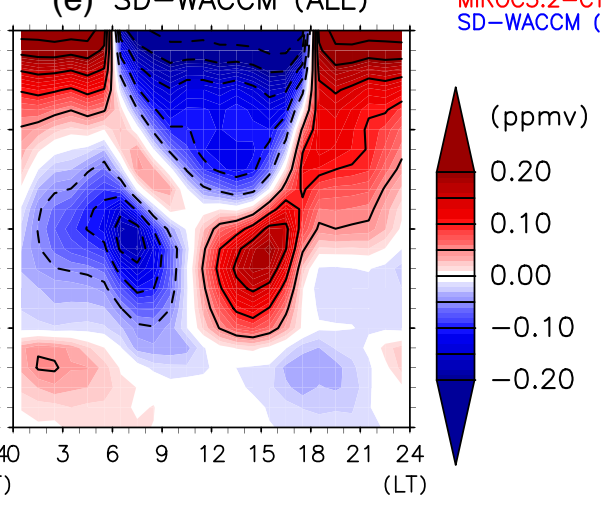

Figure 5. Vertical distribution of diurnal ozone variations averaged over $10^{\circ} \mathrm{S}-10^{\circ} \mathrm{N}$ derived from (a) SMILES, (b) MIROC3.2-CTM at SMILES observation locations and times, (c) SD-WACCM at SMILES observation locations and times, (d) full-grid MIROC3.2-CTM dataset, and (e) full-grid SD-WACCM dataset. Contour interval: 0.05 (ppmv); color scale bar is shown. A low-pass filter (three-point running mean in both the time and vertical domains) was applied to Figures $5 \mathrm{a}-5 \mathrm{c}$ to improve the presentation; e.g., the data at (01:00 LT, $22 \mathrm{~km})$ is the average of the following five data points: (00:00LT, $22 \mathrm{~km}$ ), (02:00LT, $22 \mathrm{~km}),(01: 00 \mathrm{LT}, 20 \mathrm{~km}),(00: 00 \mathrm{LT}, 22 \mathrm{~km})$, and (01:00LT, $24 \mathrm{~km})$. (f) Daily-mean values for (black curve) SMILES, (red curve) MIROC3.2-CTM, and (blue curve) SD-WACCM.

$40 \mathrm{~km}$; i.e., the center of the positive (negative) anomaly is 15:00 LT (09:00 LT) at $35 \mathrm{~km}$ and shifts with altitude, reaching 20:00 LT (05:00 LT) at $45 \mathrm{~km}$ (Figure 5). Above $50 \mathrm{~km}$, ozone is depleted after dawn and recovers after sunset, and the amplitudes associated with this simple day-night contrast increase with altitude. Note that the lower limit of the dominance of these diurnal variations is located at $50 \mathrm{~km}$ for the SMILES data but at about $46 \mathrm{~km}$ for the CTM data. This results in smaller amplitudes in the SMILES data than in the CTMs at 50-60 km (Figure 5; also see Figure 4a), while the agreement between SMILES and the CTMs (particularly SD-WACCM) is again reasonable above $65 \mathrm{~km}$ (not shown). These differences may result from some uncertainties in the photochemistry within the CTMs that determines the daynight contrast (partitioning within the odd oxygen).

[26] Figure 6 shows the latitude distributions of the diurnal variations from SMILES and the CTMs at different altitudes. Again, we confirmed that the SMILES results are reproduced quite well by CTM-SMILES and also that the effects of any sampling issues were negligible at $40^{\circ} \mathrm{S}-40^{\circ} \mathrm{N}$ (not shown). At $24 \mathrm{~km}$, we see that the distinct variations are confined to the tropics. At $34 \mathrm{~km}$, the variations are seen at all latitudes, but only during the daytime, while the amplitude is larger in the Southern Hemisphere (summer hemisphere) than that in the Northern Hemisphere. At $44 \mathrm{~km}$, the variations are again broadly uniform at all latitudes but locally enhanced in the tropics (e.g., 18:00-20:00 LT at the equator). These local peaks correspond to the enhanced maxima in the late afternoon seen in Figure 4b. At $54 \mathrm{~km}$, a distinct day-night contrast is seen with larger amplitudes in the Northern Hemisphere (winter hemisphere).

[27] We will now briefly compare our findings with previous studies. The day-night contrast seen from the upper stratosphere to the lower mesosphere is already well known [e.g., Vaughan, 1982; Huang et al., 1997; 2010], but the maximum during the late afternoon in the tropics $(40-50 \mathrm{~km})$ has been identified for the first time here. In the middle stratosphere (30-40 km), the afternoon maximum is consistent with recent results from ground-based [Haefele et al., 2008] and satellite measurements [Huang et al., 1997, 2010], but the minimum after sunset (clearly seen here) was not mentioned in these earlier researches. In the lower stratosphere (20-30 km), previous observational studies did not provide robust results (as mentioned in section 1); however, this study has obtained the first observational results that are consistent with models (CTMs) and that can be quantitatively interpreted (section 4.2).

[28] We also analyzed SABER data from the SMILES observation period and compared the results with those from 

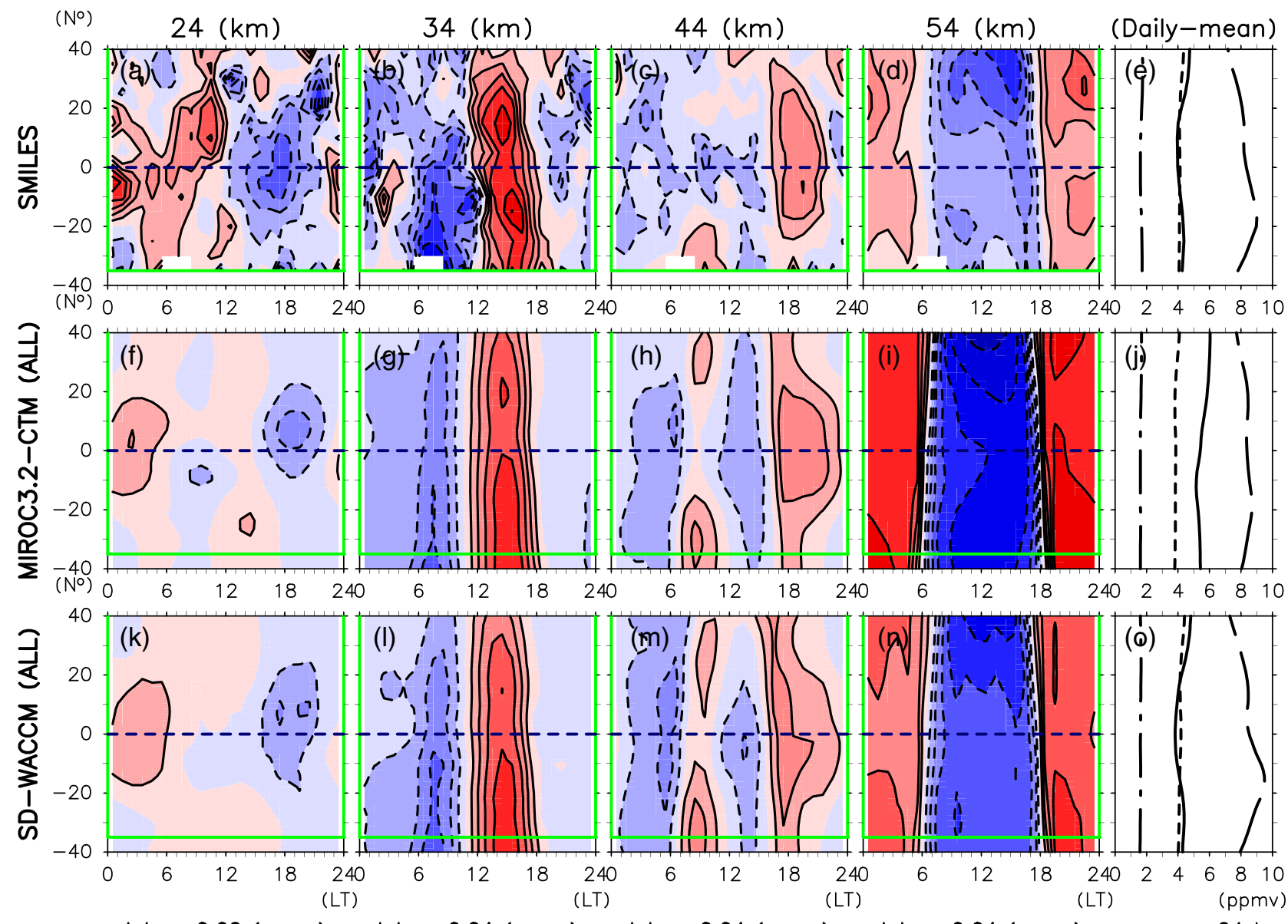

Int. $=0.02($ ppmv $)$
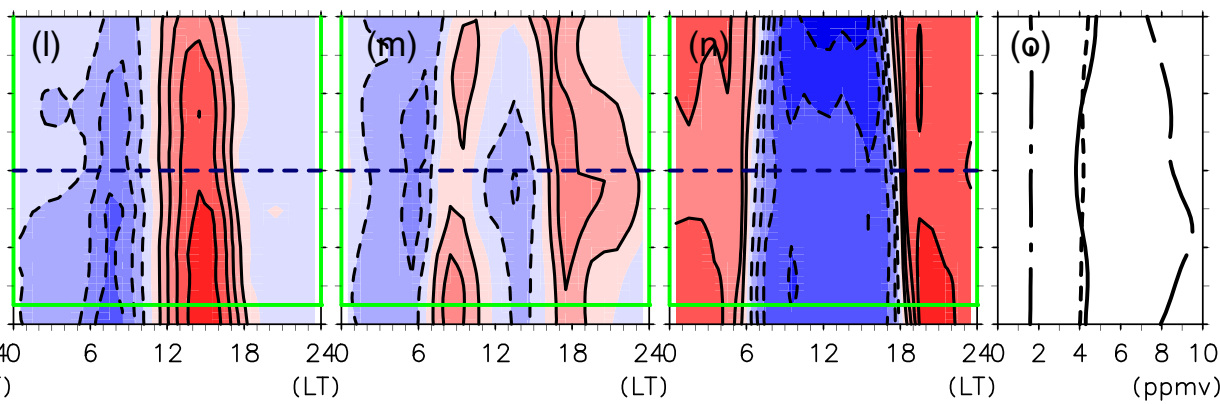

Int. $=0.04(\mathrm{ppmv})$

Int. $=0.04(\mathrm{ppmv})$

Int. $=0.04(\mathrm{ppmv})$

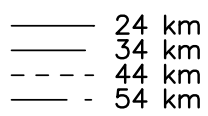

Figure 6. Latitudinal distribution $\left(40^{\circ} \mathrm{S}-40^{\circ} \mathrm{N}\right)$ of diurnal ozone variations at (a, f, k) $24 \mathrm{~km},(\mathrm{~b}, \mathrm{~g}, 1) 36 \mathrm{~km}$, (c, h, m) $44 \mathrm{~km}$, and (d, i, n) $50 \mathrm{~km}$, from (top) SMILES, (middle) MIROC3.2-CTM with full-grid data, and (bottom) SD-WACCM with full-grid data. A low-pass filter (three-point running mean in both the time and latitude domains) was applied to improve the presentation in the top panels (SMILES). The latitude region for SMILES observation is indicated by the green square. The equator is represented by a purple dashed line. Contour interval: 0.02 ppmv for (a, e, i) and 0.04 ppmv in the other panels. (e, j, o) Daily-mean values at $24 \mathrm{~km}$ (solid curve), $34 \mathrm{~km}$ (long-dashed curve), $44 \mathrm{~km}$ (short-dashed curve), and $54 \mathrm{~km}$ (dot-dashed curve).

the SMILES and CTMs. Our comparison showed that at 20-30 km, the amplitude derived from SABER is significantly larger than that from SMILES and the CTMs, while the phase is roughly consistent among the datasets. This considerably larger amplitude has been reported previously [Huang et al., 2008]. In contrast, the diurnal variations at $30-50 \mathrm{~km}$ derived from SABER data during this period are found to be affected by sampling issues because SABER requires data from a period of 60 days data to cover an entire diurnal cycle and, consequently, is more easily affected by background changes (in this case, by the changes associated with the semi-annual oscillation (SAO)). The section $B$ provides a detailed comparison of the SMILES, SABER, and CTM datasets.

\subsection{Photochemical and Dynamical Contributions to Diurnal Ozone Variations}

[29] We will now consider the underlying mechanisms associated with the observed stratospheric diurnal ozone variations in terms of photochemistry and dynamics (transport). As diurnal ozone variations in the CTMs have been validated, the CTM results can be further analyzed to examine the underlying mechanism. Figure $7 \mathrm{a}$ shows the diurnal $\mathrm{O}_{x}$ variations from the MIROC3.2-CTM full-grid dataset (i.e., CTM-ALL data). Comparing Figure $5 \mathrm{~d}$ with Figure $7 \mathrm{a}$ shows that the diurnal ozone variations are very similar to those of $\mathrm{O}_{x}$ below 48 $\mathrm{km}$ (i.e., $\mathrm{O}_{x} \approx \mathrm{O}_{3}$ ). Above this level, diurnal variations in ozone are predominantly caused by partitioning between $\mathrm{O}$ and $\mathrm{O}_{3}$ [Vaughan, 1982; Zommerfelds et al., 1989], as outlined in section 1.

[30] Figure 7b shows the diurnal $\mathrm{O}_{x}$ variations caused by photochemistry (section 3.2). Below $42 \mathrm{~km}$, odd oxygen shows a minimum after dawn and a maximum in the afternoon, while above $42 \mathrm{~km}$, it shows a maximum after dawn and a minimum in the afternoon. These photochemical variations are qualitatively consistent with the results of photochemical modeling work [Pallister and Tuck, 1983; Huang et al., 1997] and are thought to be caused by a 


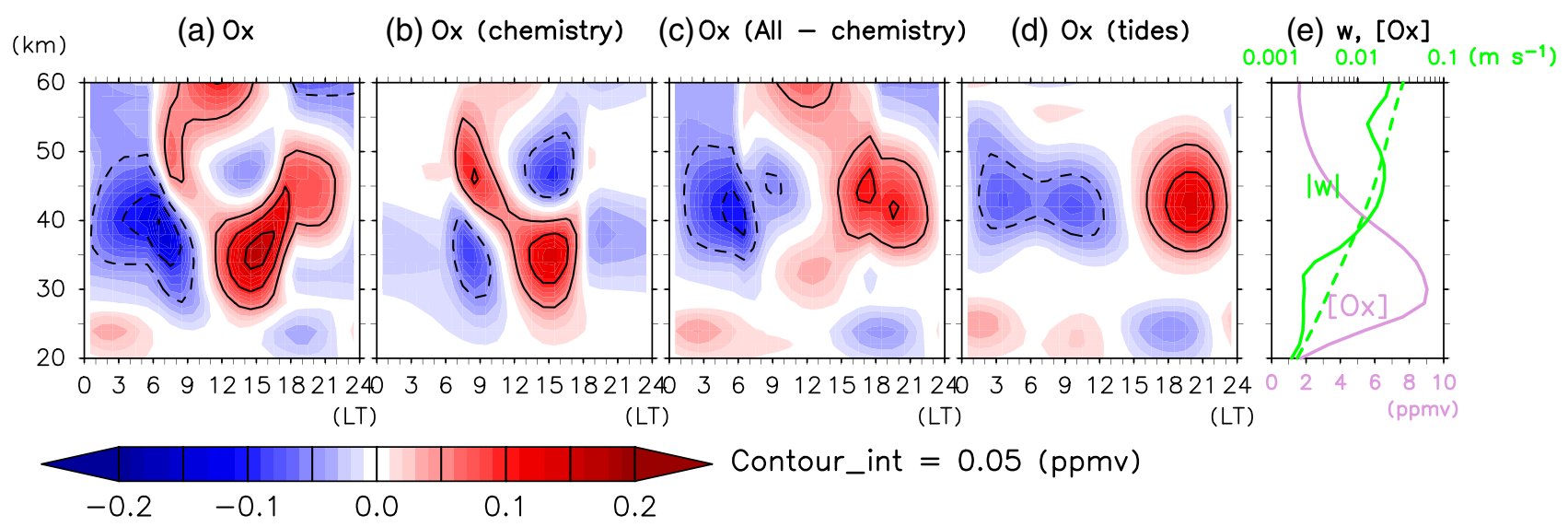

Figure 7. As for Figure 5 but for (a) odd oxygen, (b) odd oxygen caused by photochemistry, (c) (a) minus (b), and (d) estimate of odd oxygen caused by vertical transport by tidal winds, derived from MIROC3.2CTM full-grid data. Contour interval: 0.05 (ppmv). (e) Vertical profiles of $\left[\mathrm{O}_{x}\right]$ (purple curve) and the amplitude of diurnal (green solid curve) and semidiurnal (green dashed curve) vertical wind, as averaged over $10^{\circ} \mathrm{S}-10^{\circ} \mathrm{N} . X$ axis showing amplitude of vertical winds is a log scale. See text for details.

combination of the Chapman mechanism and the $\mathrm{NO}_{x} / \mathrm{HO}_{x}$ chemistry. Below $42 \mathrm{~km}$, the afternoon maximum is caused by the production of odd oxygen through the photolysis of molecular oxygen [Pallister and Tuck, 1983; Huang et al., 1997], while the dawn minimum may be partly attributed to the depletion of odd oxygen associated with the $\mathrm{NO}_{x}$ chemistry [Pallister and Tuck, 1983]. The minimum around noon above $42 \mathrm{~km}$ may be partly caused by the depletion of odd oxygen due to the $\mathrm{HO}_{x}$ chemistry [Pallister and Tuck, 1983].

[31] Figure 7c shows diurnal $\mathrm{O}_{x}$ variations caused by all dynamical effects $\left(\left[\mathrm{O}_{x}\right]^{\prime}{ }_{\mathrm{D}}\right)$, i.e., horizontal and vertical transport (section 3.2), and those that are related solely to vertical transport of daily-mean $\mathrm{O}_{x}$ by diurnal wind variations (tidal

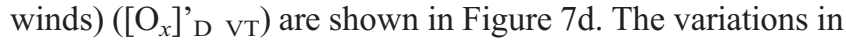
Figure $7 \mathrm{~d}$ are dominated by the diurnal harmonic component (wave number 1 component) and are reasonably consistent, quantitatively, with the results based on the all dynamical effects (Figure 7c). This suggests that vertical transport by the diurnal tide, which is mainly generated in the troposphere and propagates into the stratosphere [Chapman and Lindzen, 1970; Sakazaki et al., 2012, Sakazaki et al., manuscript in preparation, 2013], is the major dynamical factor. The dominance of the diurnal harmonic component (Figure 7d) is explained by the fact that the variations are inversely proportional to the frequency (equation (5)), although the diurnal and semidiurnal harmonic amplitudes of vertical winds are comparable between 20 and $50 \mathrm{~km}$ (Figure 7e). This dynamical variation is largest at around $25 \mathrm{~km}(0.05 \mathrm{ppmv})$ and $40 \mathrm{~km}$ $(0.1 \mathrm{ppmv})$, where the vertical gradient of $\mathrm{O}_{x},\left|\partial\left[\mathrm{O}_{x}\right] / \partial \mathrm{z}\right|$, is relatively large (Figure 7e). It may be worth noting that the observed amplitude in the lower stratosphere agrees with our estimation based on temperature tides (section 1). Figure 8 shows the latitudinal structure of the photochemical/ dynamical contributions at $44 \mathrm{~km}$ and $24 \mathrm{~km}$. As tidal vertical winds have large amplitudes in the tropics associated with the characteristic Hough mode structures [Chapman and Lindzen, 1970; Sakazaki et al., 2012], their effects appear mainly at low latitudes (Figures 8c and 8d). In contrast, the photochemical contribution essentially extends across all latitudes, although the phase differs between low-middle latitudes and high latitudes at $44 \mathrm{~km}$ (Figure $8 \mathrm{~b}$ ). Thus, the tidal contribution explains the enhanced diurnal ozone variations in the tropics at these altitudes (Figure 6).

[32] To summarize, we have shown how the observed diurnal ozone variations can be explained by a combination of photochemical and dynamical processes. In a broad sense, the variations at $20-30 \mathrm{~km}$ are caused by dynamics, those at $30-40 \mathrm{~km}$ by photochemistry, and those at $40-50 \mathrm{~km}$ by both dynamics and photochemistry. These three different regimes create a distinct altitude-latitude dependency in the amplitude and phase of the diurnal ozone variations in the stratosphere. The existence of tidal transport has been suggested previously [Huang et al., 1997; Haefele et al., 2008], but it has been confirmed and quantified for the first time here.

[33] It should be noted that the controlling processes do not change over the 6 month period, because the qualitative features of diurnal ozone variations do not change during the 6 month period as noted earlier in this section (see also section A). In fact, we checked the discussion here (Figures 7 and 8) on a monthly basis and confirmed that our conclusions do not depend on month. The magnitudes of photochemical and/or dynamical contributions, in contrast, could change with season in a quantitative way. For example, a marked seasonal variation in tides [e.g., Sakazaki et al., 2012] could result in that in amplitude of diurnal ozone variations in the lower and upper stratospheres where dynamics is important.

\subsection{Diurnal Variations in Total Column Ozone}

[34] In this section, we investigate the contribution of diurnal variations in stratospheric ozone to those in the total column ozone. Figure 9 shows the latitudinal distribution of diurnal variations in column ozone between 20 and $60 \mathrm{~km}$ based on data from SMILES and the CTMs. As was seen in the vertical/latitudinal structure (Figures 5 and 6), the SMILES results are reproduced well by CTM-SMILES. Apart from the regions poleward of $30^{\circ} \mathrm{N} / \mathrm{S}$, where the results are affected by sampling issues as inferred from the 

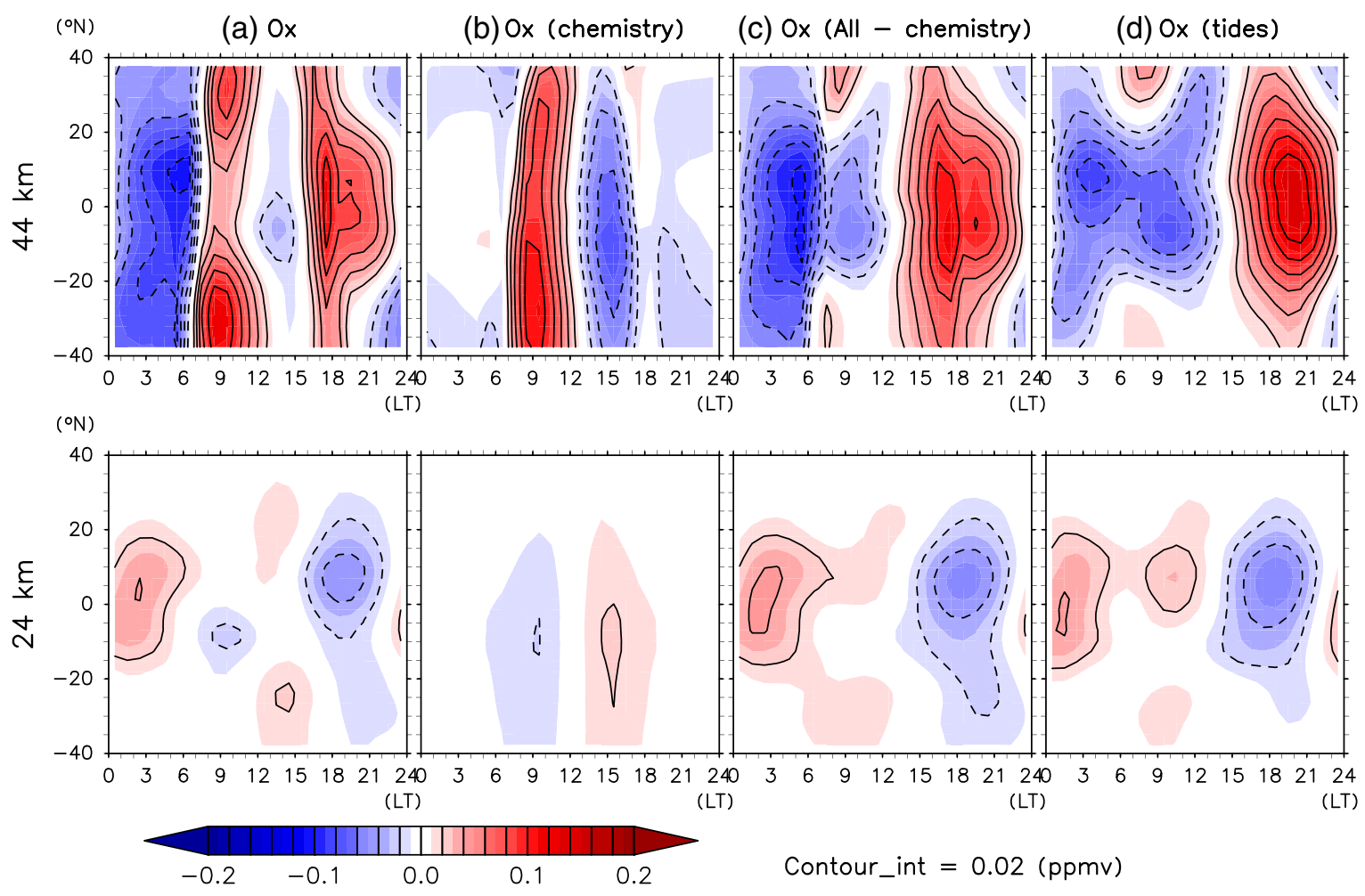

Figure 8. As for Figure 7 but for latitudinal structure at altitudes of (top) $44 \mathrm{~km}$ and (bottom) $24 \mathrm{~km}$. Contour interval: 0.02 ppmv.

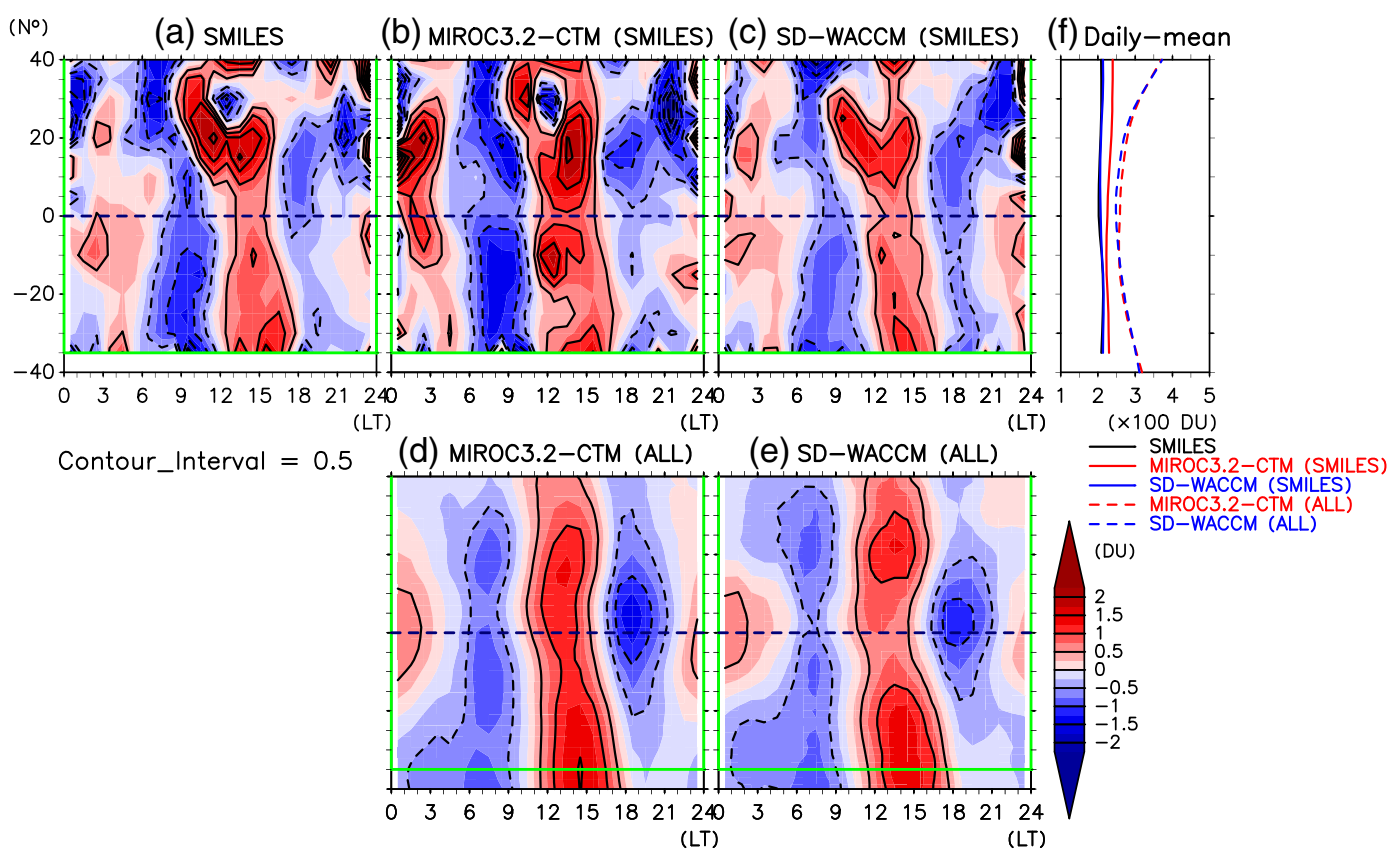

Figure 9. Latitude distributions of diurnal variations in the stratospheric column ozone (DU) calculated using data from (a) SMILES at 20-64 km, (b) MIROC3.2-CTM at SMILES observation locations and times at 20-64 km, (c) SD-WACCM at SMILES observation locations and times at 20-64 km, (d) MIROC3.2-CTM with full-grid data between 1000 and $0.1 \mathrm{hPa}$, and (e) SD-WACMM with full-grid data between 992 and $6 \times 10^{-6} \mathrm{hPa}$. A low-pass filter (three-point running mean in both the time and latitude domains) has been applied to Figures $9 \mathrm{a}-9 \mathrm{c}$ to improve the presentation. The latitude region for SMILES observation is indicated by the green square. The equator is represented by a purple dashed line. Contour interval: 0.5 DU. (f) Daily-mean values. 
difference between the CTM-SMILES and CTM-ALL data, we see semidiurnal variations in total ozone in the tropics, with an amplitude of about 1 DU (approximately $0.5 \%$ to the total column ozone), in both the SMILES and CTM data. Again, the above results do not change considerably over the 6 month at $40^{\circ} \mathrm{S}-40^{\circ} \mathrm{N}$ (section $\mathrm{A}$ and Figure A2).

[35] Figure 10 shows the vertical distributions of variations in diurnal ozone number density, which contributes to the total column ozone, averaged over $10^{\circ} \mathrm{S}-10^{\circ} \mathrm{N}$. We see that the variations at $20-45 \mathrm{~km}$ contribute most to variations in the total column ozone. As discussed in the previous section, the variations at $20-30 \mathrm{~km}$ are largely driven by dynamics, while those at $30-45 \mathrm{~km}$ are largely related to photochemistry. The total column ozone maximum (minimum) at about 15:00 LT (09:00 LT) in the tropics is caused by the variations at $30-45 \mathrm{~km}$, while the secondary maximum (minimum) at about 01:00 LT (20:00 LT) is caused by variations at $20-30 \mathrm{~km}$. Consequently, the superposition of the two different diurnal processes, with a phase shift of approximately quarter of a cycle, produces the semidiurnal variations in total column ozone.

\section{Summary and Implications}

[36] The high-quality observations made by SMILES have provided observational evidence of the global pattern of diurnal ozone variations throughout the stratosphere. Sampling issues related to inhomogeneous measurements were negligible, at least in low latitude regions. The peak-to-peak difference in the stratospheric ozone mixing ratio (total column ozone) may reach $8 \%(1 \%)$ over the course of a day. These variations are in good agreement with those from the CTMs. Analysis of the CTM data showed that these diurnal variations are caused by both photochemistry and vertical tidal transport. This study considers the 6 month mean diurnal variations during the SMILES observation period. In fact, the 6 month mean shows a good representative of the qualitative features (timing of maxima/minima) during the period for the latitude region of $40^{\circ} \mathrm{S}-40^{\circ} \mathrm{N}$. In contrast, CTM results indicate that the amplitude of the variations may change by up to $50 \%$ with month. A further investigation of seasonal dependence is a future study.

[37] Generally, extant ozone datasets are obtained at different local times depending on the measurement method. When these datasets are merged to create a unified, homogeneous time series that can be used for trend analysis [WMO, 2011], the correction of bias caused by diurnal variations between different instruments may need to be taken into account. For example, the measurement local times for the Total Ozone Mapping Spectrometer (TOMS) and the Ozone Monitoring Instrument (OMI) were 11:30 LT and 13:30 LT, respectively; the corresponding bias in ozone level due to diurnal variations is estimated to be $0.5 \mathrm{DU}(0.1 \%$ to $0.2 \%)$ for the average between $60^{\circ} \mathrm{S}$ and $60^{\circ} \mathrm{N}$, although it may not be discernible. Furthermore, the diurnal variations may need to be considered even when using one specific instrument/satellite. For example, data from the Stratospheric Aerosol and Gas Experiment (SAGE) has a bias between sunrise and sunset: the ozone level at sunset is higher than that at sunrise by around $10 \%$ at $40-50 \mathrm{~km}$ in the tropics [Mclinden et al., 2009]. This may be explained in part by diurnal variations that result in a difference of 0.15 ppmv (5\%) between sunrise (approximately 06:00 LT) and sunset (approximately 18:00 LT) (Figures 4b and 5). Also, some satellites are subject to orbital drift during operation, resulting in changes in the local time of the measurements. For example, the measurement local times of the Solar Backscatter Ultra Violet (SBUV) on board NOAA satellites change by about $10 \mathrm{~h}$ over a decade [DeLand et al., 2012]. This change corresponds to that in the stratospheric ozone mixing ratio (total column ozone) of around $8 \%(0.5 \%$ to $1 \%)$ at the maximum due to diurnal variations, which, consequently, must be removed to avoid "spurious" inter-annual variability.

[38] From the dynamical and radiative perspectives, it should be noted that in many climate models and global reanalyses, ozone amounts are treated as constant throughout the day. However, this study suggests that diurnal variations should be taken into account when attempting to calculate radiative processes to an accuracy of less than a few percent.

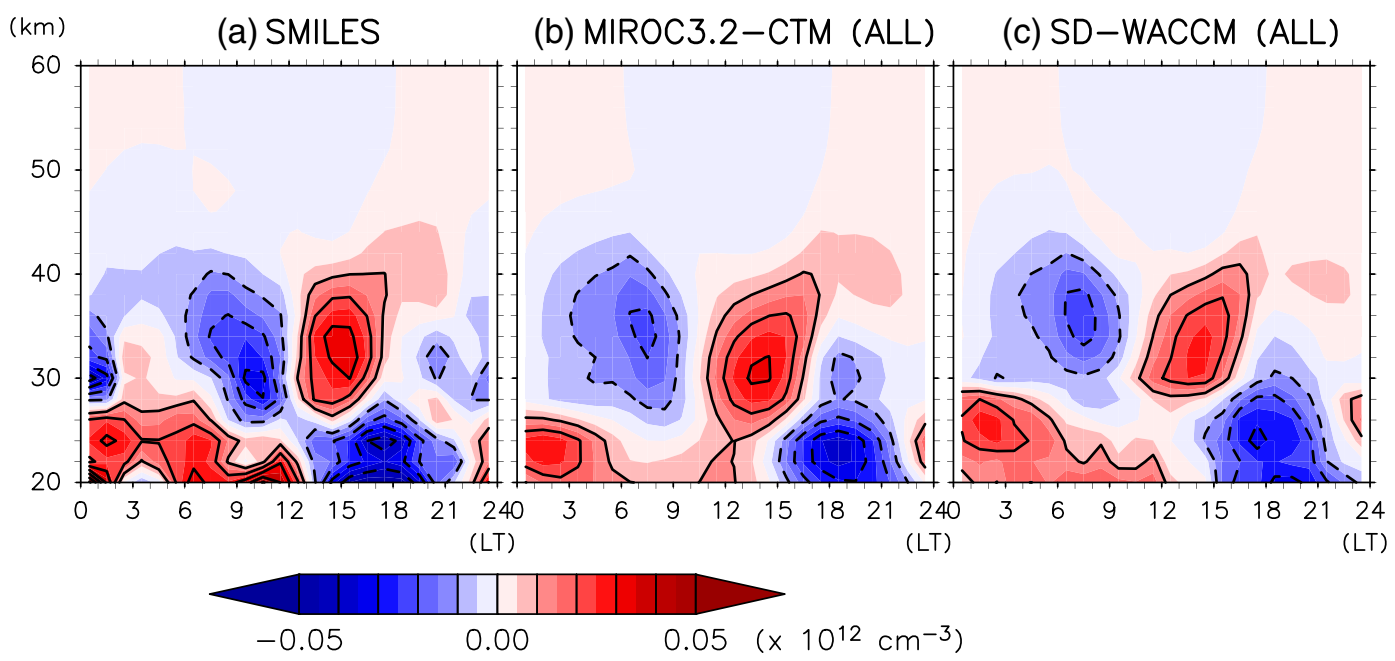

Figure 10. Vertical distribution of variations in diurnal ozone number density (molecules $\mathrm{cm}^{-3}$ ) at $10^{\circ} \mathrm{S}-10^{\circ} \mathrm{N}$, derived from (a) SMILES, (b) full-grid MIROC3.2-CTM dataset, and (c) full-grid SD-WACCM dataset. A low-pass filter (three-point running mean in both the time and altitude domains) has been applied to Figure 10a to improve the presentation. Contour interval: $0.01 \times 10^{12} \mathrm{~cm}^{-3}$; color scale bar is shown. 
[39] Another important outcome of this study is that chemistry-climate models (CCMs) with constraint of the meteorological fields such as temperature and winds, and probably chemistry-transport models (CTMs) involving the data assimilation system, may be able to accurately represent the space-time structure of minor species and, possibly, the resulting radiative processes. This indicates that the most important parameter to be determined should be the atmospheric temperature for chemical processes and the derived wind fields for transport processes. To date, there are some temperature measurements up to the upper stratosphere, while almost no operational observations are made in the mesosphere. We believe that accurate temperature measurements for the whole middle atmosphere such as SABER and MIPAS, combined with use of the chemistry-transport model, may be able to provide realistic assessments of the space-time variations of minor species such as ozone.

[40] Acknowledgments. SMILES data were provided by the ISAS/ JAXA. We thank the SABER science team (Jim Russell) for providing the data used in this study (the data were obtained by FTP from ftp://saber.gatsinc.com/custom/Temp_O3/). COSMIC data were obtained from the COSMIC Data Analysis and Archive Center (CDAAC). We thank Eriko Nishimoto for her help with the download and analysis of the COSMIC dataset. MERRA data were provided by NASA/GSFC/GMAO. We thank Hiroo Hayashi and Fumio Hasebe for helpful discussions and also Kenshi Takahashi, Pawan Bhartia, and Anne Smith for their valuable comments on the original manuscript. We are grateful to Chikako Takahashi for developing the retrieval system for the SMILES data. T. Sakazaki was supported in part by the Ministry of Education, Culture, Sports, Science and Technology (MEXT), Japan through a Grant-in-Aid for JSPS Fellows (22002958). This study was supported in part by the MEXT through a Grant-in-Aid for Scientific Research (22310010), the ISS Science Project Office of Institute, JAXA/ISAS, and the Global Environment Research Fund of the Japanese Ministry of the Environment (A-0903). Computations for MIROC3.2-CTM were made on the NEC SX-8R computers at the Center for Global Environmental Research (CGER), National Institute for Environmental Studies (NIES). The authors also thank the MIROC model development group in the Atmosphere and Ocean Research Institute (AORI) of University of Tokyo, the Japan Agency for Marine-Earth Science and Technology (JAMSTEC), and NIES, and K. Sudo in Nagoya University and T. Miyasaka at the FUJITSU FIP Corporation for assistance with MIROC3.2-CTMs development. The National Center for Atmospheric Research (NCAR) is sponsored by the U.S. National Science Foundation.

\section{Appendix A: Seasonal Dependence of Diurnal Variations Within the SMILES Observation Period}

[41] As noted in section 3.1, this study investigates the diurnal variations averaged over the 6 month period for the SMILES observation. This section briefly examines the seasonal dependence within the 6 month, using the CTM data which have been validated thorough this study.

[42] Figure A1 shows the latitude distributions of diurnal ozone variations from MIROC3.2-CTM data at different altitudes for November 2009, January 2010, and March 2010, as well as the results averaged over the 6 month (the same as Figure 6). The whole latitude region from $90^{\circ} \mathrm{S}$ to $90^{\circ} \mathrm{N}$ is shown. SD-WACCM basically shows similar results (not shown). It is found that for the altitude region where photochemistry is important $(34 \mathrm{~km}, 44 \mathrm{~km}, 54 \mathrm{~km})$, a strong seasonal dependence is seen for the latitude region poleward of $40^{\circ}$ where the local time of sunset and sunrise changes significantly with month. For example, at $34 \mathrm{~km}$, not only the amplitude but also the phase (timing of maxima/minima) at $40^{\circ} \mathrm{S}-80^{\circ} \mathrm{S}$ and $40^{\circ} \mathrm{N}-80^{\circ} \mathrm{N}$ changes considerably between November-January and March.
[43] In contrast, the results for the latitude region of $40^{\circ} \mathrm{S}-40^{\circ} \mathrm{N}$ do not change within the 6 month period in a qualitative way; the timing of maxima and minima changes little $(<1 \mathrm{~h})$. This finding suggests that the controlling process as discussed in section 4.2 does not depend on season at least for this latitude region. Here it may be worth noting that the amplitude has a seasonal dependence of up to $\sim 50 \%$ at some locations. The difference from the 6 month mean is up to $0.01 \mathrm{ppmv}$ at $24 \mathrm{~km}$ and up to $0.05 \mathrm{ppmv}$ at $34 \mathrm{~km}, 44 \mathrm{~km}$, and $54 \mathrm{~km}$ (the typical amplitude of diurnal variation is $0.05 \mathrm{ppmv}$ at $24 \mathrm{~km}, 0.15 \mathrm{ppmv}$ at $34 \mathrm{~km}, 0.1 \mathrm{ppmv}$ at $44 \mathrm{~km}$, and $0.1 \mathrm{ppmv}$ at $54 \mathrm{~km}$ ). For example at $44 \mathrm{~km}$, we see in Figure A1 that the local maximum at $18 \mathrm{LT}, 0^{\circ} \mathrm{N}$ is $\sim 0.15$ ppmv in January while it is $\sim 0.08 \mathrm{ppmv}$ in March. Section 4.2 shows that this maximum is caused by vertical transport by tidal winds. In fact, this seasonal dependence is consistent with that of tides as reported, e.g., by Sakazaki et al. [2012] who showed that the tidal amplitude is up to $~ 50 \%$ larger in January-February and in July-September than that in other months.

[44] Figure A2 shows the latitude distributions of the diurnal variations in total ozone from MIROC3.2-CTM for November 2009, January 2010, and March 2010, as well as the results averaged over the 6 month (the same as Figure 9). As inferred from the results in ozone mixing ratio (Figure A1), the timing of maxima/minima do not change considerably with season for the latitude region of $40^{\circ} \mathrm{S}-40^{\circ} \mathrm{N}$. The detailed seasonal dependence will be studied in a future work.

\section{Appendix B: Comparison of the SMILES, SABER and CTM Datasets}

[45] We also analyzed TIMED/SABER Version 1.07 data from the $9.6 \mu \mathrm{m} \mathrm{O}_{3}$ band [Russell et al., 1999; Rong et al., 2009]. As is the case for SMILES, SABER is in a nonSun-synchronous orbit, and a full diurnal cycle is covered by collecting 60 days worth of data. The latitudinal coverage is $52^{\circ} \mathrm{S}-52^{\circ} \mathrm{N}$, while the vertical coverage is $20-120 \mathrm{~km}$. Note that because there are a large number of outliers in the data from the lower stratosphere [Rong et al., 2009], we screened the data prior to the further analysis described below. That is, we first removed extreme values $(>100$ ppmv). Next, we calculated the median at each altitude level, and values that deviated from the median by $>3 \sigma$ were regarded as outliers; this process was repeated until no outliers remained (Figures B1 and B2).

[46] Using datasets corresponding to the SMILES observation period, we extracted the Sun-synchronous diurnal variations using the same method as for SMILES, except that the 60 day running mean was subtracted from the original time series in advance (note: the 30 day mean was used for SMILES). For the two CTMs, we prepared and analyzed a subset of the data that was sampled at the nearest time and grid point to the SABER measurements; these datasets are referred to as CTM-SABER.

[47] Figure A1 is the same as Figure 4 but shows the results from SABER, CTM-SABER, and CTM-ALL. SMILES results from Figure 4 are also shown. Note that the $y$ axis range is larger than that in Figure 4. At $44 \mathrm{~km}$, the SABER results are reasonably consistent with those from CTM-SABER, but there is a large difference in the results obtained from CTM-SABER and CTM-ALL/SMILES. This 


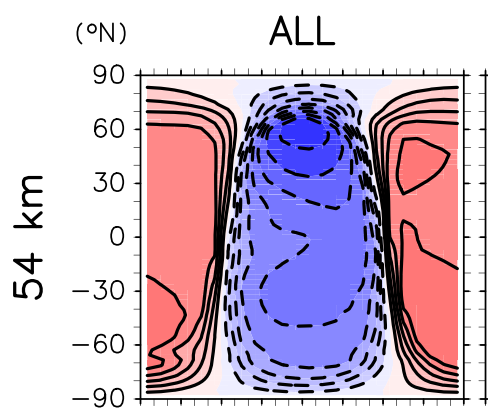

Nov. 2009

Jan. 2010

Mar. 2010
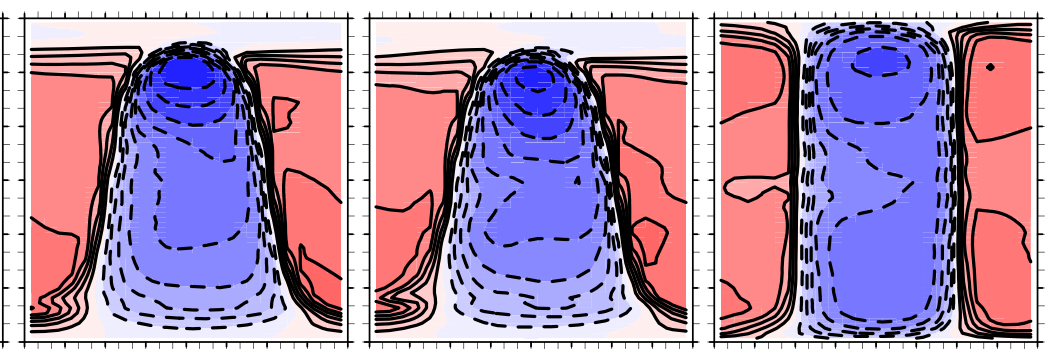

$(\mathrm{N}){ }^{0} \quad 3 \quad 6 \quad 912151821240$

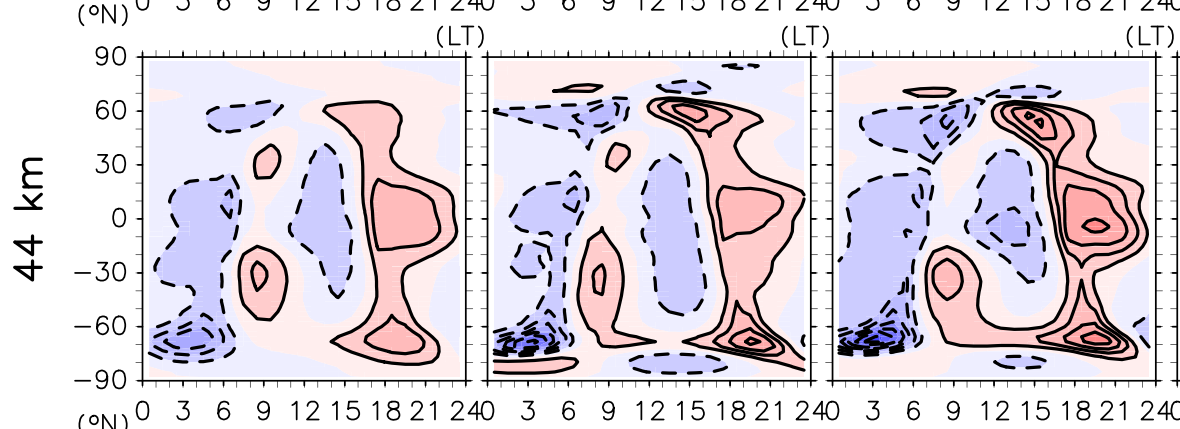

(LT)
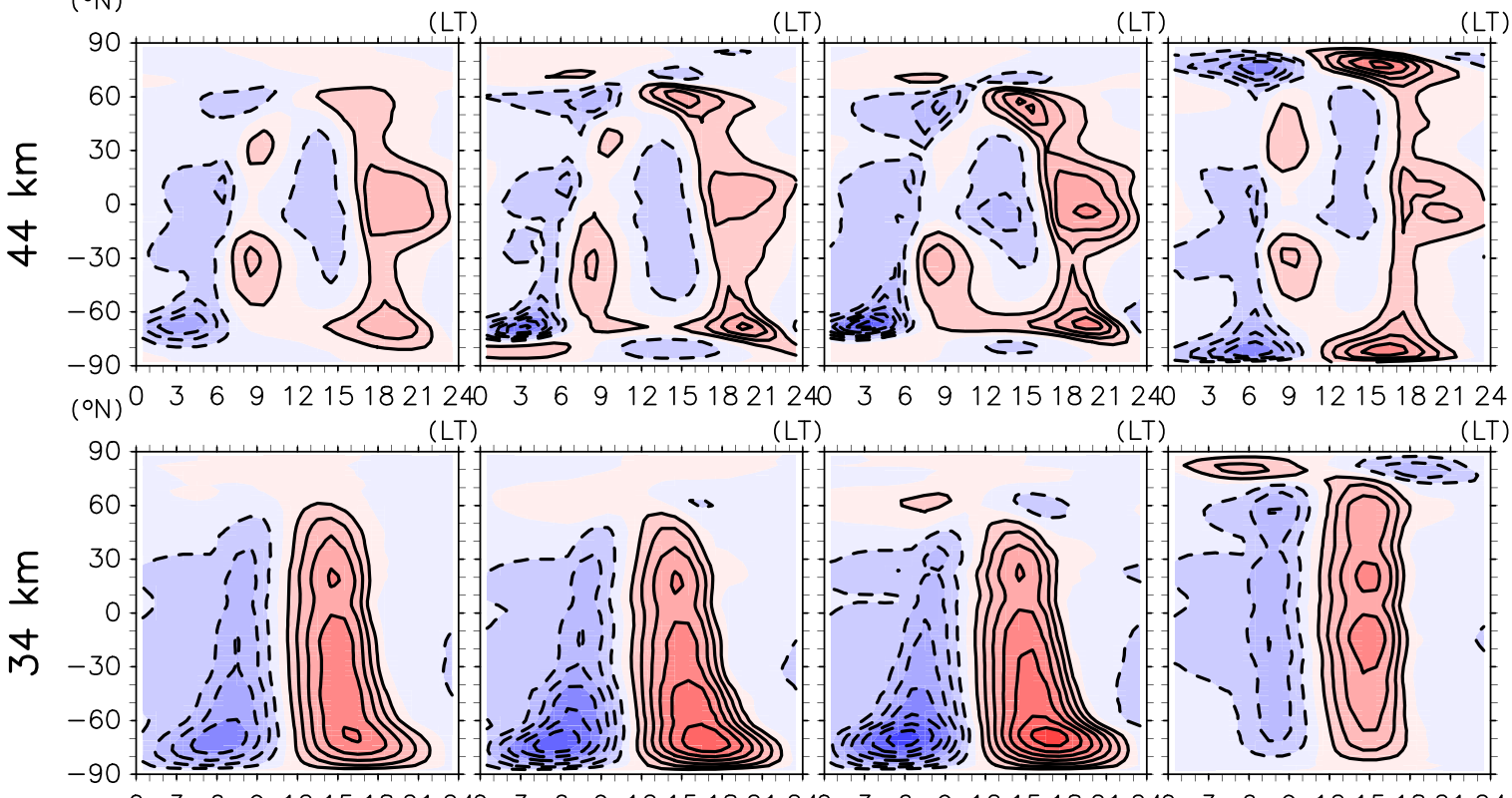

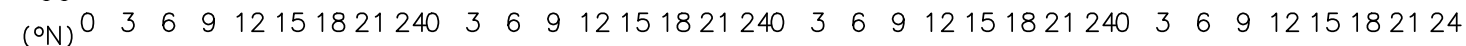

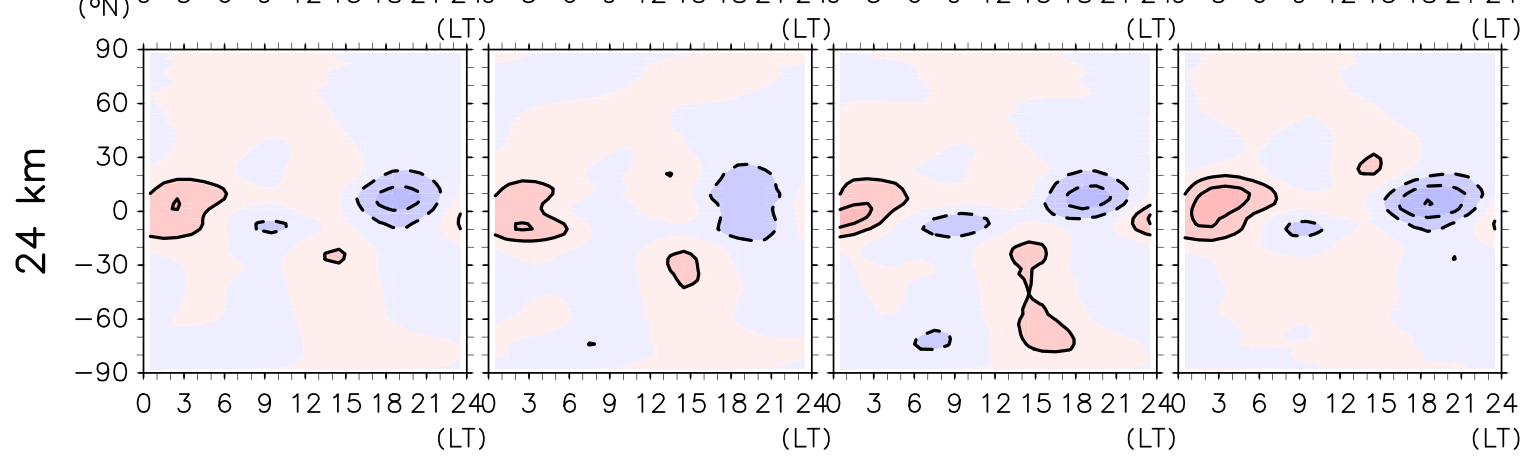

Figure A1. As for Figure 6 but for the whole latitude region at (from bottom to top) $24 \mathrm{~km}, 34 \mathrm{~km}, 44 \mathrm{~km}$, and $54 \mathrm{~km}$, as derived from MIROC3.2-CTM data. Left panels show the results averaged for the 6 month period during the SMILES observations (the same as in Figure 6), while middle-left, middleright, and right panels show the results averaged for November 2009, January 2010, and March 2010, respectively. Contour interval is $0.02 \mathrm{ppmv}$ for $24 \mathrm{~km}$ and $0.04 \mathrm{ppmv}$ for $34 \mathrm{~km}, 44 \mathrm{~km}$, and $54 \mathrm{~km}$.

finding indicates that sampling issues are non-negligible at this altitude. In fact, we confirmed that the variations associated with the stratospheric semi-annual oscillation (SAO) in the tropics are not completely removed with the 60 day mean, and so they contaminate the diurnal variations. Note that this may be the primary cause of the considerable difference between CTM-SMILES in Figure 4 and CTM-SABER in Figure A1, while the CTM-ALL data are, by definition, the same in both Figures 4 and A1. At $24 \mathrm{~km}$ and $34 \mathrm{~km}$, the phase in the SABER results is roughly consistent with those in SMILES and the CTMs. However, there is a significant difference in amplitude between SABER and CTM-SABER/CTM-ALL/SMILES; i.e., the SABER amplitude is more than 5 times larger than the others at $24 \mathrm{~km}$. Huang et al. [2010] also reported similar amplitude and phase at $20-30 \mathrm{~km}$.

[48] Considering that diurnal ozone variations in the lower stratosphere are controlled by tidal transport (section 4.2), it may be argued that the vertical tidal winds in the CTMs could be underestimated. To investigate this issue, we compared the 


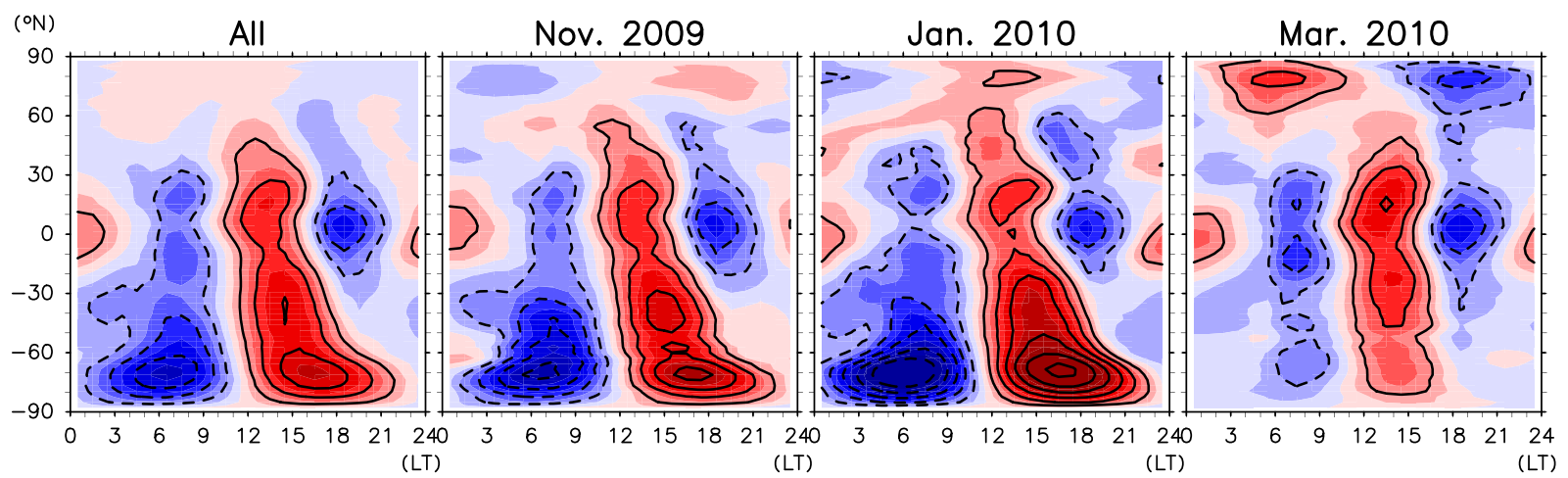

Figure A2. As is for Figure A1 but for the diurnal variations in total ozone as derived from MIROC3.2-CTM data. Contour interval is $0.5 \mathrm{DU}$.

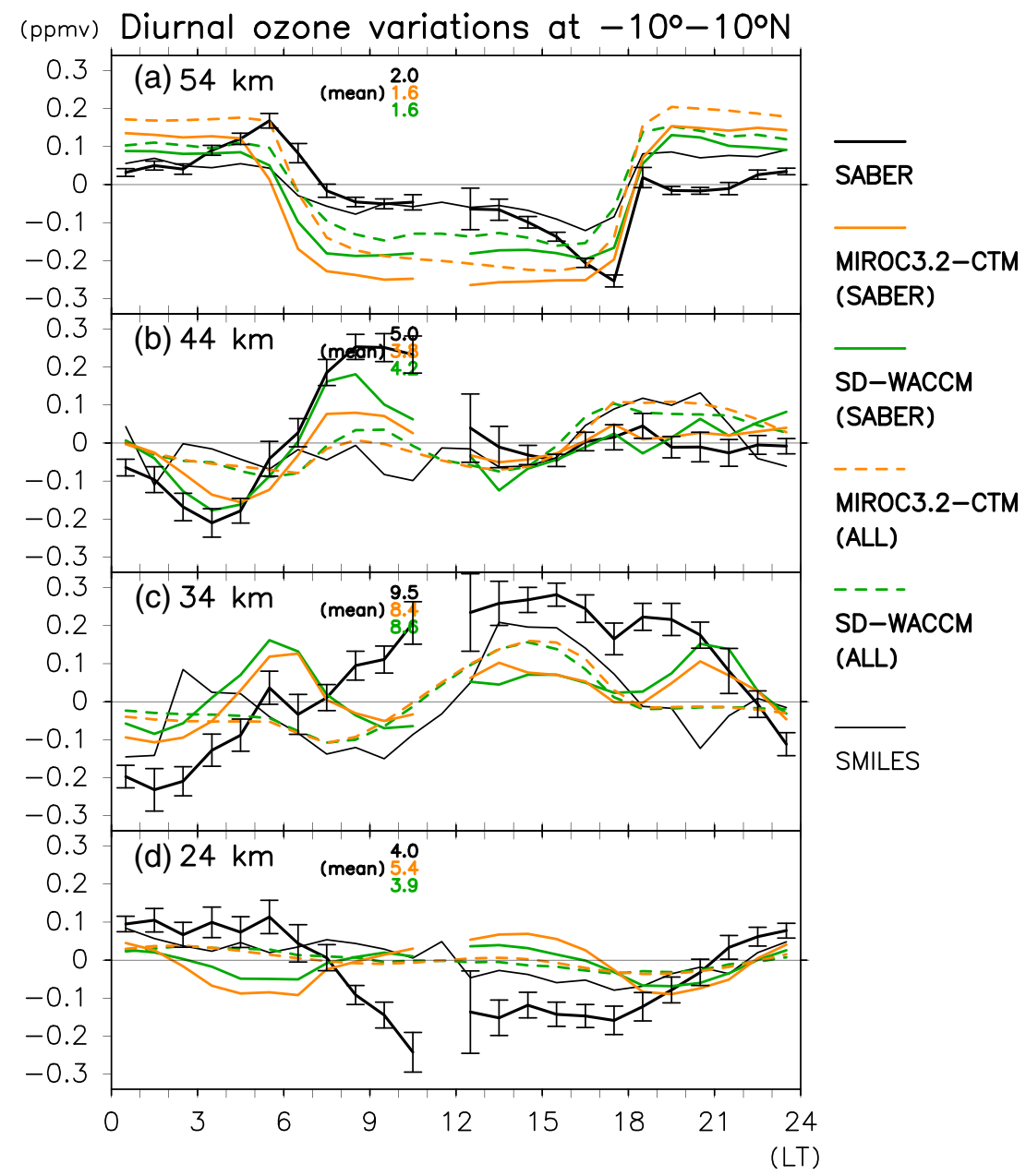

Figure B1. As for Figure 4 but showing a comparison between SABER and CTMs. Solid curves show SABER results, while orange (green) solid curves show the results from MIROC3.2-CTM (SD-WACCM) at SABER observation locations and times. SMILES results from Figure 4 are also shown by thin solid curves for reference. Note that the $y$ axis range is larger than that in Figure 4, indicating SABER's larger amplitudes.

vertical winds in the CTMs with those in the global reanalysis data from the Modern Era Retrospective analysis for Research and Applications (MERRA) [Rienecker et al., 2011]. Sakazaki et al. [2012] report that MERRA reproduces stratospheric diurnal temperature tides well. Also, in this study, we confirmed that diurnal temperature tides in MERRA are consistent with observational data from GPS radio occultation (GPS-RO) measurements with the Constellation Observing System for Meteorology, Ionosphere, and Climate (COSMIC) [Anthes et al., 2008] (not shown). Figure A2 shows vertical 

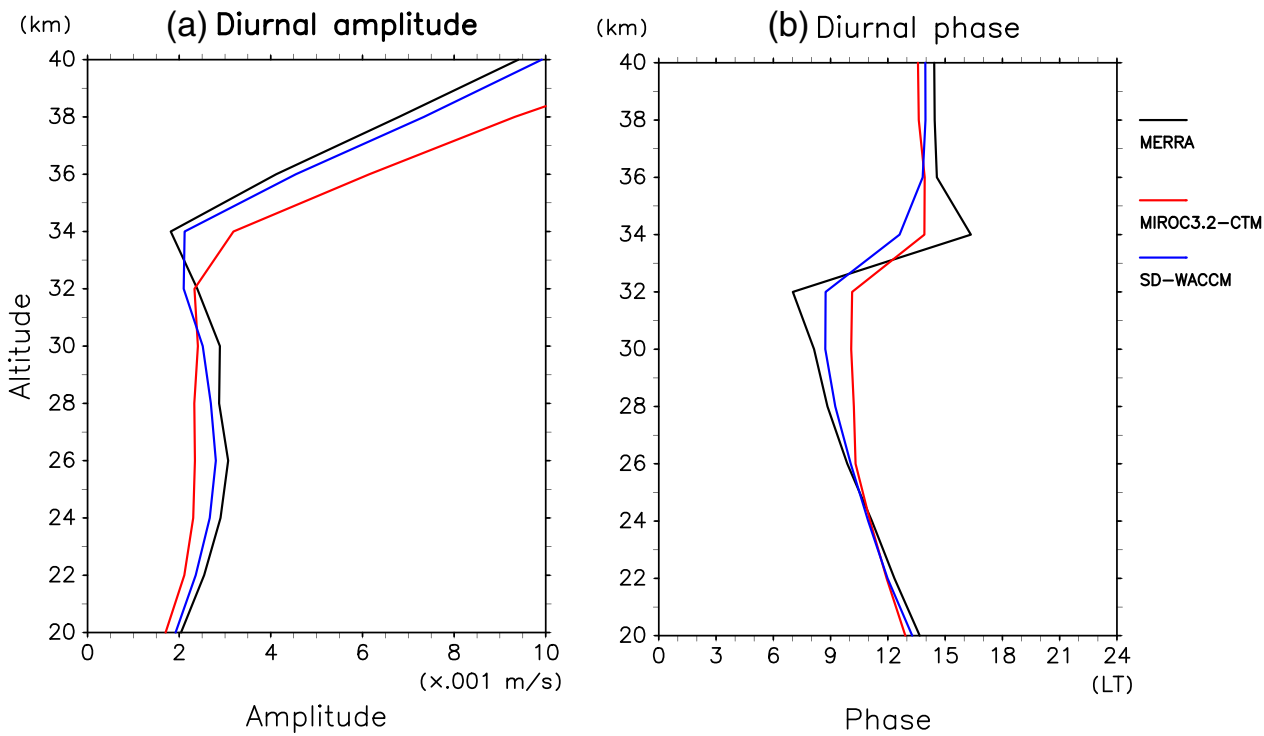

Figure B2. Vertical profiles of the (a) amplitude and (b) phase of the Sun-synchronous diurnal component in vertical wind during the SMILES observation period between $20 \mathrm{~km}$ and $40 \mathrm{~km}$, averaged over $10^{\circ} \mathrm{S}-10^{\circ} \mathrm{N}$. Black curves are for MERRA, red curves MIROC3.2-CTM, and blue curves SD-WACCM.

profiles of the amplitude and phase of the diurnal component in vertical wind from different datasets during the SMILES observation period for altitudes between $20 \mathrm{~km}$ and $40 \mathrm{~km}$, averaged over $10^{\circ} \mathrm{S}-10^{\circ} \mathrm{N}$. We see that the amplitudes and phases in the CTMs are both consistent with those in MERRA, although the amplitude in MIROC-3.2 is around $30 \%$ smaller than MERRA in the lower stratosphere. It should be noted that even if this underestimation is taken into account, the amplitudes in the SABER data, being more than 5 times larger than those in the CTMs, are still too large to be interpreted.

[49] Therefore, we conclude that the significant difference in the amplitude of diurnal ozone variations in the lower stratosphere cannot be attributed to the performance of the CTMs and that SABER data may not be appropriate for this kind of analysis at altitudes below $40 \mathrm{~km}$ at least during this analysis period.

\section{References}

Akiyoshi, H., L. B. Zhou, Y. Yamashita, K. Sakamoto, M. Yoshiki, T. Nagashima, M. Takahashi, J. Kurokawa, M. Takigawa, and T. Imamura (2009), A CCM simulation of the breakup of the Antarctic polar vortex in the years 1980-2004 under the CCMVal scenarios, J. Geophys. Res. 114, D03103, doi:10.1029/ 2007JD009261.

Anthes, R. A., et al. (2008), The COSMIC/FORMOSAT-3 mission: Early results, Bull. Am. Meteorol. Soc., 89, 313-333.

Brasseur, G. P., and S. Solomon (2005), Aeronomy of the Middle Atmosphere, Springer, Netherlands.

Chapman, S., and R. S. Lindzen (1970), Atmospheric tides, D. Reidel, New York.

Dee, D. P., et al. (2011), The ERA-Interim reanalysis: Configuration and performance of the data assimilation system, Q. J. R. Meteorol. Soc. 137, 533-597.

DeLand, M. T., S. L. Taylor, L. K. Huang, and B. L. Fisher (2012), Calibration of the SBUV version 8.6 ozone data product, Atmos. Meas. Tech., 5, 2951-2967.

Dikty, S., H. Schmidt, M. Weber, C. von Savigny, and M. G. Mlynczak (2010), Daytime ozone and temperature variations in the mesosphere: A comparison between SABER observations and HAMMONIA model, Atmos. Chem. Phys., 10, 8331-8339.
Forbes, J. M., X. Zhang, S. Palo, J. Russell, C. J. Mertens, and M. Mlynczak (2008), Tidal variability in the ionospheric dynamo region, J. Geophys. Res. 113, A02310, doi:10.1029/2007JA012737.

Haefele, A., K. Hocke, N. Kämpfer, P. Keckhut, M. Marchand, S. Bekki, B. Morel, T. Egorova, and E. Rozanov (2008), Diurnal changes in middle atmospheric $\mathrm{H}_{2} \mathrm{O}$ and $\mathrm{O}_{3}$ : Observations in the Alpine region and climate models, J. Geophys. Res., 113, D17303, doi:10.1029/2008JD009892.

Huang, F. T., C. A. Reber, and J. Austin (1997), Ozone diurnal variations observed by UARS and their model simulation, J. Geophys. Res., 102(D11), 12971-12985.

Huang, F. T., H. G. Mayr, J. M. Russell III, M. G. Mlynczak, and C. A. Reber (2008), Ozone diurnal variations and mean profiles in the mesosphere, lower thermosphere, and stratosphere, based on measurements from SABER on TIMED, J. Geophys. Res., 113, A04307, doi:10.1029/2007JA012739.

Huang, F. T., H. G. Mayr, J. M. Russell III, and M. G. Mlynczak (2010), Ozone diurnal variations in the stratosphere and lower mesosphere, based on measurements from SABER on TIMED. J. Geophys. Res. 115, D24308, doi:10.1029/2010JD014484.

Imai, K., et al. (2012a), Comparison of ozone profiles between Superconducting Submillimeter-Wave Limb-Emission Sounder (SMILES) and worldwide ozonesonde measurements, J. Geophys. Res., submitted.

Imai, K., et al. (2012b), Validation of ozone data from the Superconducting Submillimeter-Wave Limb-Emission Sounder (SMILES), J. Geophys. Res., submitted.

Kikuchi, K., et al. (2010), Overview and early results of the Superconducting Submillimeter-Wave Limb-Emission Sounder (SMILES), J. Geophys. Res., 115, D23306, doi:10.1029/2010JD014379.

Kunz, A., L. L. Pan, P. Konopka, D. E. Kinnision, and S. Tilmes (2011), Chemical and dynamical discontinuity at the extratropical tropopause based on START08 and WACCM analyses, J. Geophys. Res. 116, D24302, doi:10.1029/2011JD016686.

Marsh, D. R., W. R. Skinner, A. R. Marshall, P. B. Hays, D. A. Ortland, and J.-H. Yee (2002), High Resolution Doppler Imager observations of ozone in the mesosphere and lower thermosphere. J. Geophys. Res., 107(D19), 4390, doi:10.1029/2001JD001505.

Mclinden, C. A., S. Tegtmeier, and V. Fioletov (2009), Technical Note: A SAGE-corrected SBUV zonal-mean ozone data set, Atmos. Chem. Phys., 9, 7963-7972.

Mitsuda, C., et al. (2011), Current status of level 2 product of Superconducting Submillimeter-Wave Limb-Emission Sounder (SMILES), Proc. SPIE, 8176, 81760M.

Pallister, R. C., and A. F. Tuck (1983), The diurnal variation of ozone in the upper stratosphere as a test of photochemical theory, Q.J. R. Meteorol. Soc., 109, 271-284.

Ricaud, P., J. de La Noë, B. J. Connor, L. Froidevaux, J. W. Waters, R. S. Harwood, I. A. MacKenzie, and G. E. Peckham (1996), Diurnal variability of mesospheric ozone as measured by the UARS microwave limb sounder instrument: Theoretical and ground-based validations, J. Geophys. Res., 101, 10077-10089. 


\section{SAKAZAKI ET AL.: DIURNAL VARIATION IN STRATOSPHERIC OZONE}

Rienecker, M. M. et al. (2007), The GEOS-5 data assimilation system: Documentation of versions 5.0.1, 5.1.0, and 5.2.0., Tech. Rep. Ser. On Global Modeling and Data Assimilation, NASA/TM-2007-104 606, 27.

Rienecker M. M. et al. (2011), MERRA: NASA's Modern-Era Retrospective analysis for Research and Applications, J. Clim., 24, 3624-3648.

Rong, P. P., J. M. Russell III, M. G. Mlynczak, E. E. Remsberg, B. T. Marshall, L. L. Gordley, and M. López-Puertas (2009), Validation of Thermosphere Ionosphere Mesosphere Energetics and Dynamics/Sounding of the Atmosphere using Broadband Emission Radiometry (TIMED/SABER) $\mathrm{v} 1.07$ ozone at $9.6 \mu \mathrm{m}$ in altitude range $15-70 \mathrm{~km}, J$. Geophys. Res. 114, D04306, doi:10.1029/2008JD010073.

Russell, J. M., III, M. G. Mlynczak, L. L. Gordley, J. J. Larry Tansock, and R. Esplin (1999), Overview of the SABER experiment and preliminary calibration results, Proc. SPIE Int. Soc. Opt. Eng., 3756 , $277-288$.

Sakazaki, T., M. Fujiwara, X. Zhang, M. E. Hagan, and J. M. Forbes (2012), Diurnal tides from the troposphere to the lower mesosphere as deduced with TIMED/SABER satellite data and six global reanalysis data sets, J. Geophys. Res., 117, D13108, doi:10.1029/2011JD017117.
Schneider, N., F. Selsis, J. Urban, O. Lezeaux, J. de La Noë, and P. Ricaud (2005), Seasonal and diurnal ozone variations: Observations and modeling, J. Atmos. Chem., 50, 25-47.

Takahashi, C., S. Ochiai, and M. Suzuki (2010), Operational retrieval algorithms for JEM/SMILES level 2 data processing system, Journal of Quantitative Spectroscopy \& Radiative Transfer, 111, 160-173.

Takahashi, C., et al. (2011), Capability for ozone high-precision retrieval on JEM/SMILES observation, Adv. Space Res., 48, 1076-1085.

Vaughan, G. (1982), Diurnal variation of mesospheric ozone. Nature, 296, $133-135$.

World Meteorological Organization (2011), Scientific assessment of ozone depletion: 2010, Report 52, Global Ozone Research and Monitoring Project.

Zeng, Z., W. Randel, S. Sokolovskiy, C. Deser, Y.-H. Kuo, M. Hagan, J. Du, and W. Ward (2008), Detection of migrating diurnal tide in the tropical upper troposphere and lower stratosphere using the Challenging Minisatellite Payload radio occultation data, J. Geophys. Res., 113, D03102, doi:10.1029/2007JD008725.

Zommerfelds, W. C., K. F. Kunzi, M. E. Summers, R. M. Bevilacqua, D. F. Strobel, M. Allen, and W. J. Sawchuck (1989), Diurnal variations of mesospheric ozone obtained by ground-based microwave radiometry, J. Geophys. Res., 94 (D10), 12819-12832. 